\title{
Networking Between Ethnomathematics, STEAM Education, and the Globalized Approach to Analyze Mathematical Connections in Daily Practices
}

\author{
Camilo Andrés Rodríguez-Nieto ${ }^{1,2^{*}}$ (D) Ángel Alsina $^{3}$ (D) \\ ${ }^{1}$ Atlantic University (UA), Atlántico, COLOMBIA \\ 2 National Open and Distance University (UNAD), COLOMBIA \\ 3 University of Girona, Girona, SPAIN
}

Received 19 November 2021 • Accepted 15 January 2022

\begin{abstract}
Ethnomathematics, STEAM Education, and the Globalized Approach are articulated to analyze mathematical connections in daily practices. For this, the networking strategies were considered (understand the theoretical approaches; contrast-compare; coordinate-combine; synthesize-local integration). In the coordination and comparison, the complementarities between the approaches were evidenced and based on these, an empirical phenomenon was analyzed on the connections in daily practices carried out by five artisans who worked in the elaboration of kites, cabinets, masks, and drawers, agriculture, and masonry. From the integration strategy, three results were identified: (i) intra-disciplinary connections, which make it possible to present mathematics as an integrated whole, rather than as a set of isolated knowledge; (ii) interdisciplinary connections, between knowledge from different disciplines that feed into each other; and (iii) connections between the mathematics practiced by cultural groups with institutionalised mathematics that are, at the same time, globalized because they relate mathematics to the socio-cultural context.
\end{abstract}

Keywords: networking of theories, ethnomathematics, STEAM education, globalized approach, daily practice

\section{INTRODUCTION}

Contemporary mathematics curricula are characterized by fostering student understanding, rather than pure mechanization. The emphasis on understanding requires, among other aspects, emphasizing connections, since "when students can connect mathematical ideas, their understanding is deeper and more lasting" (National Council of Teachers of Mathematics-NCTM, 2000, p. 64). NCTM (2000) indicates that teaching programmes at all levels should enable all students to: recognise and use connections between mathematical ideas, understand how mathematical ideas interconnect and build on each other to produce a coherent whole, and recognise and apply mathematics in non-mathematical contexts. According to these three standards, Alsina (2014) points out that mathematical connections refer to the relationships between different mathematical contents and between mathematical contents and processes (intradisciplinary connections), the relationships of mathematics with other disciplines (interdisciplinary connections), and the relationships of mathematics with the environment (globalized approach).

Some authors consider the establishment of connections fundamental, given that they are relevant to promote the understanding and usefulness of mathematics (Alsina, 2020; García-García \& DoloresFlores, 2020; Rodríguez-Nieto, 2020, 2021; RodríguezNieto et al., 2020, 2021a, 2021b, 2021c). Various theoretical approaches also value mathematical connections. For example, realistic mathematics education (RME) proposes the intertwinement principle, according to which mathematical topics should be connected to each other (Freudenthal, 1991). There are also other approaches that promote a view of mathematics in connection with elements of a different nature. Considering their impact, we focus on the following three:

1. Ethnomathematics, a research programme that has taken on the study of mathematics practised

(c) 2022 by the authors; licensee Modestum. This article is an open access article distributed under the terms and conditions of the Creative Commons Attribution License (http://creativecommons.org/licenses/by/4.0/).

$\square$ camiloarodriguez@mail.uniatlantico.edu.co (*Correspondence) $\square$ angel.alsina@udg.edu 


\section{Contribution to the literature}

- Intra-disciplinary connections, which make it possible to present mathematics as an integrated whole, rather than as a set of isolated knowledge.

- Interdisciplinary connections, between knowledge from different disciplines (STEAM) that feed into each other.

- Connections between the mathematics practiced by cultural groups with institutionalised mathematics that are, at the same time, globalized because they relate mathematics to the socio-cultural context (Ethnomathematics).

by cultural groups and which promotes a humanistic mathematics that connects ancestral and everyday knowledge with mathematics developed in the classroom (D'Ambrosio, 2001; Gerdes, 2013),

2. Science, technology, engineering, art, mathematics (STEAM education), which proposes that the connections between various disciplines should occupy an important place in classrooms at all stages, so that mathematics can be worked on in connection with science, technology, engineering, and art (Alsina, 2020), and

3. the globalized or globalising approach, which refers to how we approach knowledge of reality and how it is perceived and involves a totalising intentionality in terms of the elements that make it up (Delanty, 2000; Parjanadze, 2009).

In this article, we are interested in the analysis of mathematical connections from these three approaches assuming, on the one hand, that the current moment is characterised by the integration of knowledge through connections to promote the understanding and usefulness of mathematics and, on the other hand, that different theoretical frameworks can provide different elements that contribute to enriching this analysis, considering that the three theoretical approaches share and value the sociocultural perspective of mathematics. In this context, the purpose of this article is to propose an integrated framework of analysis based on a networking where the contributions of Ethnomathematics, STEAM education, and the globalized approach are combined to study daily practices and the connections established between them. It is important to network between these theoretical approaches because analysing everyday practices with only one of them may miss important aspects that are shared by all three and that are useful to complement and strengthen the analysis. The theoretical approaches of interest and that will be integrated in this work have not been previously articulated. The goal is to connect theories that have aspects in common or that are unconnected, while respecting their principles and methods (Prediger et al., 2008).

Ethnomathematics has previously been networked with the onto-semiotic approach-OSA (Oliveras \& Godino, 2015), showing that they complement each other. For example, one of the complementarities from the epistemic and ecological facet is that ethnomathematics seeks to improve the teaching and learning of mathematics based on a cultural background, asking "What are the mathematical practices carried out in traditional cultures, ethnic or social groups?" and OSA asks "What are the institutional mathematical practices and the configurations of objects and processes involved in them required to solve mathematical problem-situations?" Oliveras and Godino (2015) conclude that, "the epistemological and historical questions that are of interest to ethnomathematics can be expressed in the terms of OSA, since the notion of institution is general and encompasses any kind of 'community of practice'" (p. 445). Whereas STEAM education and the globalized approach were combined to address the issue of mathematical connections based on a mathematical literacy model for early childhood education (Alsina, 2020).

Now, some research on networking has been carried out with two theories, for example, between the OSA and the APOS theory (Font et al., 2016), between the OSA and the theory of instrumental genesis (Drijvers et al., 2013), between the OSA and the extended theory of connections-ETC (Rodríguez-Nieto et al., 2021b), among other research (Artigue \& Mariotti, 2014; BiknerAhsbahs \& Vohns, 2019). Furthermore, "the networking of theories is an increasingly common and powerful approach to analyzing complex phenomena such as learning processes in classrooms" (Tabach et al., 2020, p. $1)$.

\section{THEORETICAL FRAMEWORK: THREE DIFFERENT THEORETICAL APPROACHES}

\section{The Ethnomathematics Program}

The fundamental principle of ethnomathematics is the exploration and appreciation of the mathematics used by cultural groups and not only to consider Western mathematics. In other words, it is interested in the connection between the abstract mathematical world and everyday life. This was D'Ambrosio's (1995, 2001) main goal when he initiated this programme. D'Ambrosio (1995) referred to the fact that in the use of mathematics there is a predominance of measuring, 
counting and modelling processes that were gradually organised according to their logical structure in different practices developed in medieval times, for example, in mercantile arithmetic, in the geometrical potential used in constructions, in designs, painting, drawing and astrological practices. This diversity of practices was organised by Bishop (1999) and he identified six universal activities: designing, counting, measuring, playing, explaining and locating, which stimulate people's cognitive processes. The term ethnomathematics has had several conceptualizations, highlighting culture and etymology, ethnomathematics such as

\footnotetext{
"the mathematics practiced by cultural groups, such as urban and rural communities, groups of workers, professional classes, children in a given age group, indigenous societies, and so many other groups that are identified by the objectives and traditions common to these groups (D’Ambrosio, 2001, p. 9)."
}

Etymological definition considering three roots centred on the ways, styles, arts, ideas, and techniques of measuring, calculating, comparing, counting, and classifying (tics) to explain, learn, know, deal in/with, understand phenomena (mathema) in certain natural, social, cultural (ethno) environments (D'Ambrosio, 2014; Rosa \& Orey, 2016). However, Aroca (2016, p. 192) states that the etymological definition of ethnomathematics should be expanded, given that
"it is not only the socio-cultural, it is also the historical, the political, the ethical, its relationship with education, training, pedagogy, didactics, the religious, the economic, the psychological, the linguistic that mediate the teaching and learning of mathematics, and not all of these dimensions can be interpreted through the mathematic techniques in an ethno."

Other themes based on ethnomathematics are the six dimensions: cognitive, conceptual, educational, epistemological, historical, and political (Rosa \& Orey, 2016). Ethnomathematics "studies the multifaceted relationships and interconnections between mathematical ideas and other cultural elements, such as language, art, crafts, construction, education" (Gerdes, 2013, p. 150). In other words, ethnomathematics allows connections to be made between everyday experiences with institutional mathematics and can contribute to the understanding of mathematical concepts (RodríguezNieto, 2020), and, in addition, emphasises the importance of communities in relation to the school environment, because it connects mathematics with cultural practices developed and used locally (Rosa \& Orey, 2018, p. 72). In short, the relationship between mathematics as evidenced in everyday human practices and institutionalised mathematics has been referred to as the ethnomathematical connection (Rodríguez-Nieto, 2021).

In this context of ethnomathematical connections, Rodríguez-Nieto (2020) has analysed the typology of internal and external connections between measurement systems, but also, they can be identified in design processes, counts, explanations, locations, play, estimates, among other universal activities. An internal connection refers to "the relationships that a subject makes between units of measurement (conventional or non-conventional) of the same system of measurement used in an everyday practice, considering equivalences and conversions" (Rodríguez-Nieto, 2020, p. 12), and external connections "are promoted when a unit of measurement (conventional or non-conventional) is used in a similar way in different systems of measurement in different daily practices" (RodríguezNieto, 2020, p. 26). It should be noted that these types of connections depend on the meaning and use that the person gives to the unit of measurement in his or her daily practice.

From ethnomathematics, several works of research have explored daily practices, such as kite fishing where two systems of non-conventional measures were identified, including the fathom, the quarter, the 'jeme', the distance between the tips of the forefinger and thumb when fully extended, or the finger, used with the fishing gear and in the construction of the kite depending on the wind and the phases of the moon (Rodríguez-Nieto et al., 2019b). Other research focused on fishing nets identified the fathom as a non-conventional measure, among others (Chieus, 2009). Also, there are studies focused on recognising the measurements used in the elaboration of cassava buns (Rodríguez-Nieto et al., 2019a), works inspired by the mathematical richness implicit in masonry (Rey \& Aroca, 2011), calculation practices by indigenous people of Cigugur to determine the best time to start housing construction activities, identifying arithmetic operations, sets, congruences, etc. (Umbara et al., 2021).

Castro et al. (2020) inquired about the mathematical notions developed by a carpenter in the making of furniture and ships, highlighting the use of the metre, centimetre, inch, and tolerance. Paternina-Borja et al. (2020) analysed the designs of masks and moulds evidencing symmetries and measurements with fingers, and pencil. In the elaboration and use of the 'güilile' carrying basket, García-García and Bernandino-Silverio (2019) identified geometric knowledge such as the parabola, circumference, parallel lines, and the use of the hand span.

Supiyati et al. (2019) recognised anthropometric measurements such as 'seperunjung', 'sedepa' (fathom), 'karang ulu' (height of person), and 'senyari' (width of index finger); and concepts such as angle, triangle, and cylinder in cultural aspects of Sasak culture architectures 
and constructions. Sunzuma and Maharaj (2019) found that in-service teachers have well-grounded ethnogeometric knowledge as they recognise mathematics in traditional dances, round huts, pottery, carpentry, welding, and sewing, which is an important input for teaching geometry. In addition, Sunzuma and Maharaj (2020) stated that ethnomathematical approaches must be integrated into geometry classes and teachers must be trained for this. Rodríguez-Nieto (2021) explored the ethnomathematical connections between geometric concepts (cylinder, circumference, measurement of areas, volume, etc.) in the elaboration of tortillas in Mexican culture. In addition, he proposed situations for teaching mathematics with paper and pencil and with GeoGebra emphasising the construction of the 'tortilla'. In terms of methods, in ethnomathematics, data can be collected by conducting fieldwork to observe the practices of different cultural groups based on ethnography, conducting videotaped interviews, taking field notes and drawing pictures, which is analysed in detail in terms of what people do and why they do it (D'Ambrosio \& Knijnik, 2020).

\section{STEAM Education}

Changes in the social, cultural, technological, and economic framework have generated new educational and relational contexts. There have been transformations not only in the way of capturing and receiving information but also in the way of constructing knowledge, which has led many researchers to reflect on the new needs of schools in the 21st century and on how to ensure that education and training systems adapt to the demands of the knowledge society (Martín Carrasquilla, 2020). For this author, then, the need arises to break down the barriers between disciplines, from an orientation that integrates them into the real world to address new realities, promoting relevant and authentic learning experiences (Vásquez et al., 2013) as is the case of STEAM education.

In Europe, for example, this concern was highlighted in the reports 'Europe needs more scientists' at the beginning of the 21st century (European Communities, 2004) or "Science education now: A new pedagogy for the future of Europe", also known as the Rocard Report (European Communities, 2007), while in the USA it has a long tradition, initiated in the post-Sputnik era with the acronym SMET and which has nowadays re-emerged strongly (Zollman, 2012). Both in the USA and Europe, the main reason for governmental, business and social interest in this interdisciplinary approach is to improve the quantity, and more recently also the quality and diversity, of SMET, STEM, or STEAM professionals, which is considered essential to ensure the desirable economic and social progress. Thus, in the diversity of programmes, reports and proposals linked to this integrated approach, similar concerns can be found, which Zollman (2012) summarises as problems in guaranteeing the supply of STEAM professionals and problems in guaranteeing knowledge and innovation for all workers of the future in a technified world, together with what schools (and other non-formal educational agents) 'have to do' to solve these two problems. Secondly, there is the need for citizen literacy in the scientific-technological field.

Martín Carrasquilla (2020) makes an extensive review of authors who have tried to define this literacy, with the purpose of overcoming this deficit in most government documents and programmes. Zollman (2012), for example, assumes that the construction of a definition of STEM literacy by adding the various strands of literacy (science, technology, engineering, and mathematics) defined separately dilutes the essence of each, forgets the synergy of the four aspects and does not take into account personal needs. From this point of view, Lederman (1998) describes STEM literacy as the ability to adapt and accept changes driven by the work of new technologies, to anticipate the multi-level impacts of their actions, to communicate complex ideas effectively, highlighting as an essential aspect the search for measurable and creative solutions to problems that are unimaginable today. Vásquez et al. (2013) relate this to the fact that all students can act and progress in a technological world. Balka (2011, p. 7) defines STEM literacy as "the ability to identify, apply and integrate concepts from science, technology and mathematics to understand complex problems and to innovate in their solution", bringing the idea of the development of creativity as an added value to his proposal. For Zollman (2012), STEM literacy must go beyond content, processes, meeting our social needs and our economic needs and include the development of personal needs that make us responsible and participating citizens.

It is clear, then, that STEM or STEAM literacy does not mean achieving literacy in science, technology, engineering, arts and mathematics separately. STEAM is not an acronym representing five separate subject areas, but rather, an interdisciplinary approach to learning, where rigorous academic concepts of science, technology, engineering, arts and mathematics are applied in real-world contexts that generate connections between school, community, work and global enterprise (Tsupros et al., 2009). Thus, from our perspective as researchers, trainers and teachers in science, technology and mathematics education with a critical stance, interest in STEAM education should also focus on promoting STEAM literacy for all students as a personal value in itself, with the aim of providing them with tools that enable them to identify and apply, both the key knowledge and the ways of doing, thinking, speaking and feeling of science, engineering, technology, arts and mathematics, in a more or less integrated way, to understand, decide and/or act on complex problems and to build creative and innovative solutions, taking advantage of personal synergies, and available 
technologies; and in a critical, reflective, and valuedriven way (Couso, 2017). This definition highlights the fact that STEAM literacy is a learning need that supports people's active participation in society, enabling continuous access to knowledge, learning and the development of critical and reflective thinking and values. STEAM education is not for students who excel in science or mathematics but for everyone (Martín Carrasquilla, 2020).

Several authors have introduced this vision in schools, based on practices where the goal is to promote the deep integration of various STEAM disciplines, rather than using one discipline as a tool to learn another. Belbase et al. (2021) reviewed the STEAM literature and found that the sub-constructs under STEAM education priorities were: curriculum integration in STEAM education and sub-constructs under processes classified under pedagogical and assessment in STEAM education.

\section{Globalized Approach}

Delanty (2000) indicates that the concept of globalization in education is based on psychological, sociological, epistemological and pedagogical reasons. This author, on the basis of this foundation, points out the need for the organisation of contents to have a globalising approach, so that the contents are inserted in or depend on a broader framework that allows the integration of the different contents in spheres of interpretation and significance greater than those offered by a single discipline. Very synthetically, from the social point of view, it is considered that the function of teaching is to train to understand and intervene in reality, which implies having to teach for complexity, which allows us to analyse the different types of knowledge: everyday, scientific and school knowledge and the role that each one plays in achieving this objective.

From an epistemological perspective, it allows us to differentiate between two terms sometimes understood as synonyms and sometimes, paradoxically, as antonyms: globalization and interdisciplinarity. Globalization refers to how we approach knowledge of reality and how it is perceived and involves a totalising intentionality in terms of the elements that make it up, as indicated in the introduction. Globalization, as such, is independent of the existence or non-existence of disciplines, since its aim is to tell us about how things and events in reality are global and at the same time unitary, complex and composed of multiple and highly interrelated elements (Parjanadze, 2009). On the other hand, disciplines and their different ways of relating to each other (interdisciplinarity, multidisciplinarity, transdisciplinarity, etc.) do not refer to what reality is like, but their function is to offer us the means and instruments to arrive at knowledge of it. Finally, the psycho-pedagogical foundation shows school learning as the result of a complex process of exchanges established between the students who learn, the content that is the object of learning and the teachers who help to construct meanings and to attribute meaning to what they learn. It is an interactive triangle, whose vertices are the students, the content and the teachers and which illustrates the core of the teaching and learning processes at school.

From this point of view, Parjanadze (2009) points out that the globalising perspective allows problems, situations and events to be analysed within a context and in their globality. In order to solve these problems, to understand and interpret these situations and events, different means (disciplines) are used, relating them to a greater or lesser degree (interdisciplinarity, transdisciplinarity, integration, etc.) according to the needs of understanding and analysis. It can thus be deduced that the concept of globalization does not refer to a specific methodology and does not imply a devaluation of the role of the disciplines.

The existence of various so-called globalized methods (centres of interest, projects, topics, etc.), which are evidently based on globalising principles, since their object of knowledge corresponds to a part of the students' experiential reality, does not mean that a globalising approach presupposes a certain method. The globalising perspective does not prescribe methods, but rather provides guidelines for organising and articulating knowledge in learning sequences oriented towards a specific end with meaning and intentionality and situated in contexts that allow for their significance and functionality. In addition, it characterizes each of the learning processes in their individuality, giving them meaning in terms of their immediate function for a better understanding of a given situation or as a preliminary step for a subsequent contextualised use.

From the perspective of mathematics education, Alsina (2012) indicates that teaching mathematics from a globalized approach is one of the principles of mathematics education in early childhood education, in accordance with the curricular guidelines for this educational stage. Within this framework, he stresses that one of the aims of mathematics teaching should be to help discover the mathematics that exists in everyday life so that children learn to see, interpret and understand it, so that they can progressively develop better in their immediate environment. Considering these aspects, Alsina (2020) indicates that the use of real contexts at an early age helps to promote the learning of this discipline, but above all to understand what the meaning of mathematics is, what its true functions are: formative, taking into account that the contexts of everyday life allow us to progressively move from concrete situations to abstract situations (progressive mathematization); instrumental, by considering that contexts are, in reality, tools that favour motivation, interest or the meaning of mathematics; and applied, by 
encouraging the use of mathematics in contexts that are not exclusively school-based and, therefore, promoting the formation of more mathematically competent people.

\section{METHODOLOGY}

This research is qualitative (Cohen et al., 2018), developed from the four pairs of networking strategies proposed by Prediger et al. (2008):

1. understand other theories-understand the theories to use,

2. contrast-compare,

3. coordinate-combine, and

4. synthesize-local integration, in order to integrate three theoretical approaches (ethnomathematics, STEAM, and the globalized approach), considering the similarities between them, to analyze the mathematical connections in daily practices.

For Bikner-Ahsbahs and Prediger (2010):

"The first pair of strategies (...) describes that mutual understanding of theories is necessary when researchers begin to practice networking; the second pair focuses on comparison strategies; the third pair captures the step to be taken toward other theories by linking them together; and the fourth describes the equilibrium of reducing theories by integrating at least parts of one theory into another and constructing new theories that subsume others (p. 147)."

Next, in the analysis and results sections, the networking strategies of the three theoretical approaches are developed, and particularly in this research the first two pairs of strategies were developed simultaneously and in the third pair of strategies some phases are proposed analysis with the coordination and integration of theoretical approaches.

\section{ANALYSIS}

\section{Understanding and Comparison of Theoretical Approaches}

In this research we consider that the first and second pair of networking strategies are developed in the description and understanding of the theoretical approaches presented before, where the principles and methods of each theoretical approach are evidenced. However, below we will specify about some of these aspects because to carry out the comparison, we are based on the perspective of Radford (2008), who proposed that in the theoretical articulations or networking differences and complementarities should be considered, taking into account theoretical principles, methodologies and research questions.

\section{Principles}

Initially, the ethnomathematics proposed by D'Ambrosio $(2001,2007)$ had the fundamental principle of valuing and recognizing the mathematics practiced by cultural groups when they carry out different daily practices and analyzing how people mathematize their own reality when they use mathematics in everyday life. Rosa and Shirley (2016) affirm that:

\section{"the main foundation of an ethnomathematics program is an awareness of the many ways of knowing and doing mathematics that relates to the values, ideas, notions, procedures, and practices in a diversity of contextualized environments (p. 1)."}

In addition, it is important to consider that the word ethnomathematics is etymologically structured in three roots: ethno (members of specific cultures), mathema (modeling of natural and social environments and contexts to explain and understand phenomena), and tics (measurement techniques and ideas, calculations, classification, comparison, etc.) (D'Ambrosio, 1985).

Also, it focuses on the inclusion of the ethnomathematics explored in the classroom where the teacher must manage the didactic aspects and mathematical concepts associated with the artifacts or evidenced in the measurements, counts, locations, etc. Likewise, this research program is concerned with investigating how students (by themselves or with the help of the teacher) understand and articulate and use ideas, concepts, and mathematical procedures to solve mathematical problems or those related to their sociocultural context. Other relevant principles of ethnomathematics are the six dimensions: cognitive, conceptual, educational, epistemological, historical, and political that interrelated, "aim to analyze the sociocultural roots of mathematical knowledge" (Rosa \& Orey, 2016, p. 12). Finally, ethnomathematics fosters interconnections between institutionalized mathematical ideas and other aspects of culture, education, engineering, language, art, construction, among others (Gerdes, 2013).

On the other hand, the principles and fundamental basis of STEAM education is the integration of multidisciplinary content considering the common points between five academic disciplines: science, technology, engineering, art, and mathematics (SánchezLudeña, 2019). In this context, STEAM is not an acronym that encompasses separate subject areas, but rather an interdisciplinary approach to learning, where rigorous academic concepts from science, technology, engineering, the arts, and mathematics are directed toward application in real-world contexts, building connections between school, community, work, and the global company (Tsupros et al., 2009). 
In the STEAM approach, students can develop skills in any of their areas (robotics, design and programming of applications and games, communication, and audiovisual productions, among others), which integrate or connect autonomy and entrepreneurship, collaboration and communication, knowledge and use of technology, creativity and innovation, design and manufacture of products and artifacts, critical thinking and problem solving (Sánchez-Ludeña, 2019).

Another relevant principle of STEAM education is that it is necessary, at least, to integrate two disciplines in an activity so that it can be considered a STEAM activity and that, in no case, should one discipline be considered as a context or a tool to work on another. discipline or, in other words, consider that one is at the service of the other, but rather that in a STEAM activity both disciplines feedback and enrich each other (Alsina, 2020).

Finally, the globalizing perspective is not considered as a didactic technique, but as an attitude towards the teaching process (Delanty, 2000; Parjanadze, 2009). From this point of view, globalization refers to how we approach the knowledge of reality and how it is perceived and involves a totalizing intention in terms of the elements that compose it. Globalization, as such, is independent of the existence or not of the disciplines, since its objective is to tell us about how things and events are in reality: global and at the same time unitary, complex and composed of multiple highly interrelated elements. On the other hand, the disciplines, and their different ways of relating (interdisciplinarity, multidisciplinarity, transdisciplinarity, etc.) do not refer to what reality is like, but rather their function is to offer us the means and instruments to reach its knowledge.

\section{Methods}

In ethnomathematics, it is recommended to follow a qualitative methodological path based on ethnography where, on the one hand, participant observation and semi-structured interviews are considered important for the collection of data that must primarily be video recorded. In fact, D'Ambrosio and Knijnik (2020) maintain that, to research in ethnomathematics, one must "carry out fieldwork in which ethnographic techniques are used, such as participant observation, audio recording, field diary and the interview" (p. 285). On the other hand, for data analysis it is suggested to carry out detailed qualitative analyzes of what people do and why they do it. To do this, the thematic data analysis suggested by Braun and Clarke (2006) can be used.

In relation to STEAM education, Martín-Carrascilla (2020) refers to active methodologies that are supported by cooperative learning structures and the use of organizational and methodological teaching resources that allow the integration of knowledge and facilitate the transfer of learning. Specifically, the main methodological references of the STEAM areas that this author mentions are project-based learning, centers of interest, case studies, problem-based learning, gamification, inquiry and modeling, design thinking, the maker phenomenon, or learning by design, valued as essential for the deployment of STEAM objectives.

In the globalized approach, the existence of a series of methods called globalized (centers of interest, complexes of interest, projects, topics, etc.), which obviously start from globalizing principles, since their object of knowledge corresponds to a parcel of the experiential reality of the student does not mean that a globalizing approach inevitably presupposes a certain method. According to Zabala (1999), the globalizing perspective does not prescribe methods, but rather provides guidelines for organizing and articulating knowledge in learning sequences oriented to a specific purpose with meaning and intentionality and located in contexts that allow their significance and functionality. In addition, it characterizes each one of the learnings in their individuality, giving them meaning due to their immediate function for the better understanding of a given situation or as a prerequisite for a later contextualized use.

\section{Research questions}

The research questions that are asked in studies focused on ethnomathematics are mainly directed at culture and its relationship with mathematics, for example, how do people relate to their natural and sociocultural environment? How do people recognize and explain the facts and phenomena present in their lives? (D'Ambrosio, 2016). Other questions emphasize what mathematical knowledge does a person use to carry out a daily practice or make an artifact? What are the universal activities that a person activates in their daily practice? It should be noted that these questions arise when a daily practice has not been explored from the research and it is relevant to report it, or when the curricular organizations suggest that the relationships between mathematical content (measures, counts, etc.) and daily life be promoted. In addition, questions related to the teacher's knowledge have been recognized in the literature (e.g., what ethnomathematical knowledge does the teacher mobilize and activate in the classroom when he develops mathematical content?); with the curricular materials (e.g., what ethnomathematical aspects are proposed in the tasks proposed in the textbooks?); and, finally, objectives can be outlined to answer questions framed in some of the six dimensions of ethnomathematics.

In STEAM education, research questions revolve around the teacher, the student, and the tasks. The questions around the teacher have to do mainly with the teacher's knowledge (e.g., what is STEAM?, what methods can be used to carry out STEAM activities?, etc.), teaching practices (e.g., how are carries out the 


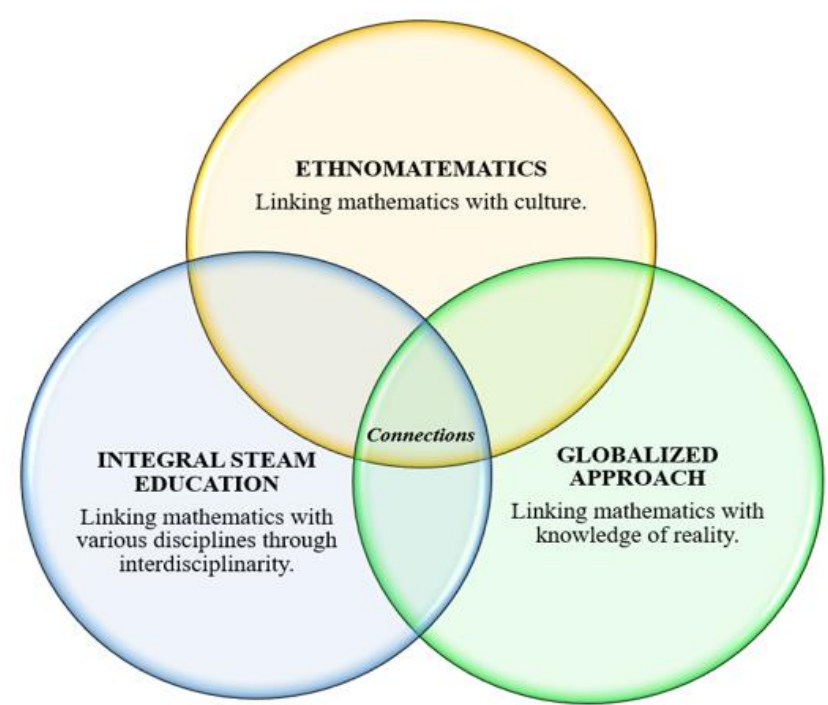

Figure 1. Articulating ethnomathematics, STEAM education, and the globalized approach to analyze connections

planning and/or management of STEAM activities?) and the teacher's conceptions (e.g., what do you think of the implementation of STEAM education in the classroom?, what benefits does it entail?, what difficulties?). Some studies also analyze the performance and attitudes of students towards the implementation of STEAM activities, which entails, above all, the construction of instruments that allow inquiring about these issues. Additionally, there are also lines of research around the type of tasks, for example, to avoid the gender gap.

Finally, in the globalized approach, the research questions are raised around three dimensions:

1. the sociological dimension, whose object of study and knowledge is what configures reality and allows autonomous action on it;

2. the epistemological dimension, which starts from the basis that the constituted knowledge has not established integrating models that give global answers to all the phenomena, for which it is essential to resort to the contributions of the different sciences. From this dimension, then, it is assumed that it is inexcusable to inquire about an educational approach that, collecting rigor of each of the sciences, offers its value by relating them, increasing their interpretative potential; and

3. the psychopedagogical dimension, from which questions are raised about the benefits and obstacles of the globalized approach, mainly.

\section{Coordinating and Combining Ethnomathematics, STEAM and the Globalized Approach}

In the third pair of strategies, the antecedents were considered to describe an integrated analysis framework of mathematical connections. In Figure 1, the most characteristic features of each approach and their relationships are presented very synthetically, based on the fact that interdisciplinarity links various disciplines to enrich each other, in a line similar to what is proposed by the integrated STEAM knowledge approach (Alsina, 2012), while the globalized approach presents similarities with the relationships established by ethnomathematics of connecting the mathematics practiced by cultural groups with institutionalized mathematics (D'Ambrosio, 2014; Rodríguez-Nieto, 2021), which, in fact, they are ethnomathematical connections (Rodríguez-Nieto, 2021).

Some authors had already begun to establish some partial articulations between the constructs addressed in this study. For example, Rosa and Orey (2021) consider it important to work on STEM from an ethnomathematical perspective, since they mention that:

"an ethnomathematics-based curriculum helps students demonstrate consistent mathematical processes as they reason, solve problems, communicate ideas, and choose appropriate representations through the development of daily mathematical practices. As well, it recognizes connections with science, technology, engineering, and mathematics (STEM) disciplines. Our pedagogical work, in relation to STEM education, is based on the trivium curriculum for mathematics and ethnomodelling, which provides communicative, analytical, material, and technological tools to the development of emic, etic, and dialogic approaches that are necessary for the elaboration of school curricula (p. 840)."

Assuming this idea, in our study the globalized approach is also added because, in addition to providing the necessary tools for the elaboration of school curricula from this double integration, it is also necessary to approach the knowledge of reality and how it is perceived, from a totalizing intention in terms of the elements that compose it. Considering these issues, Figure 1 shows the connections that arise from the integration of the three approaches: connections between mathematics and culture, between mathematics and other disciplines, and between mathematics and knowledge of reality.

In the first pairs of strategies, emphasis was placed on understanding the approaches, finding differences and similarities between them, but in the pair of coordination and combination strategies, in addition to finding complementarities, Bikner-Ahsbahs and Prediger (2010) affirm that the articulation should not be complete between the theories, but rather, they are "mainly used for a network understanding of an empirical phenomenon or a part of theoretical data" (p. 10). Thus, in this study an empirical phenomenon was developed between three phases directed towards the analysis of mathematical connections in different daily practices. 
Table 1. Information from study participants $(\mathrm{P})$

\begin{tabular}{lccccc}
\hline P & Name (pseudonym) & Age (years) & Daily practice & School level & Work experience (years) \\
\hline P1 & José & 45 & Kite maker & Bachelor & 32 \\
P2 & Pedro & 61 & Farmer \& merchant of corn, coffee, \& beans & Non-schooled & 45 \\
P3 & Andrés & 26 & Maker of cabinets, kites, \& masks & Bachelor & 10 \\
P4 & Darío & 38 & Mason \& maker of buildings & Bachelor & 20 \\
P5 & Sigifredo & 63 & Box kite maker & Bachelor & 45 \\
\hline
\end{tabular}

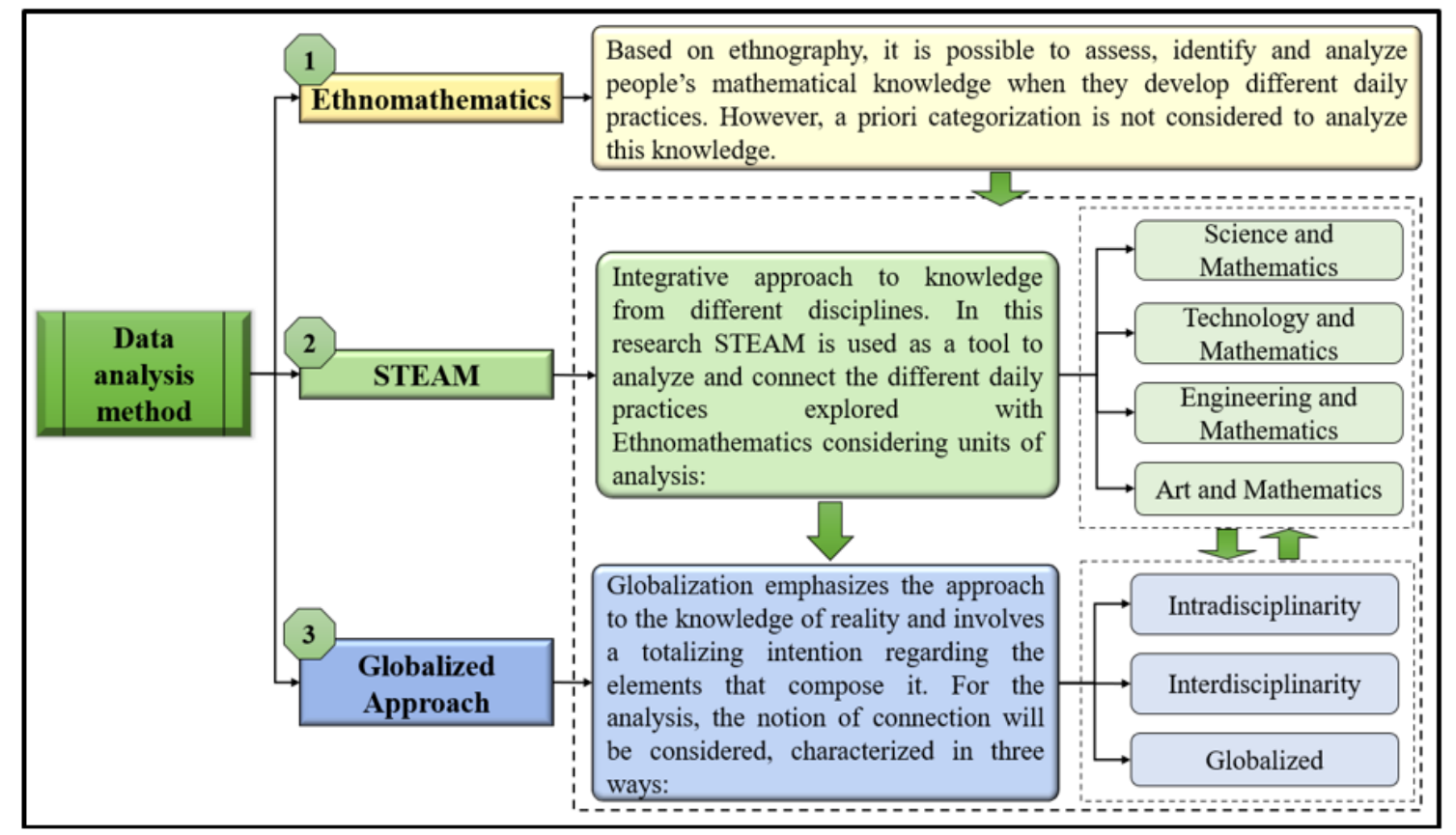

Figure 2. Phases of integrative data analysis

\section{Phase 1-Selection of study participants}

There were five merchants (P1, P2, P3, P4, and P5) who decided to participate in this research voluntarily, which are described in Table 1.

Initially, the researchers told traders that the research was for educational purposes about valuing mathematics used in everyday practices and not economic or commercial. Also, they were asked for an interview to learn about their work, and they decided to participate, that is, there was an agreement.

\section{Phase 2-Data collection}

The data were collected through ethnography that means ethnos (population, people) and grapho (writing, description) (Restrepo, 2016) based on participant observation and semi-structured interviews (Longhurst, 2010), where it was deepened on the necessary information on the development of each daily practice. Generally, the interviews were conducted in the participants' home, starting with initial questions to learn about the personal life of each of them to obtain the data systematized in Table 1. Subsequently, development questions were asked (e.g., Do you carry out your daily practice? What are the stages of making a kite? What materials do you use?) and, finally, closing questions were asked about the marketing of each product. In this sense, the ethnomathematical research perspective suggested by D'Ambrosio and Knijnik (2020) is followed, who affirm that, "most of the research in ethnomathematics implies carrying out field work in which ethnographic techniques are used as participant observation, audio recording, field diary and interview" (p. 285). It should be noted that the interviews were videotaped, photographs and field notes were taken, and the participants were asked to make drawings that represent their daily practice or some parts of it.

\section{Phase 3-Data analysis}

The data analysis was developed based on the functional, coordinated, and complementary use of the conceptual tools of each theoretical approach. In this context, we propose an analysis method (Figure 2) that consists of three phases. In the first, daily practices are explored through ethnomathematics, and the mathematical concepts of the participants are identified without considering any categorization or theoretical elements a priori. In the second, the tools of the STEAM approach (relationships between science, technology, engineering and art, and mathematics) are considered to typecast each of the daily practices. In the third phase, the mathematical connections are characterized based on the globalized approach and the model of internal and 


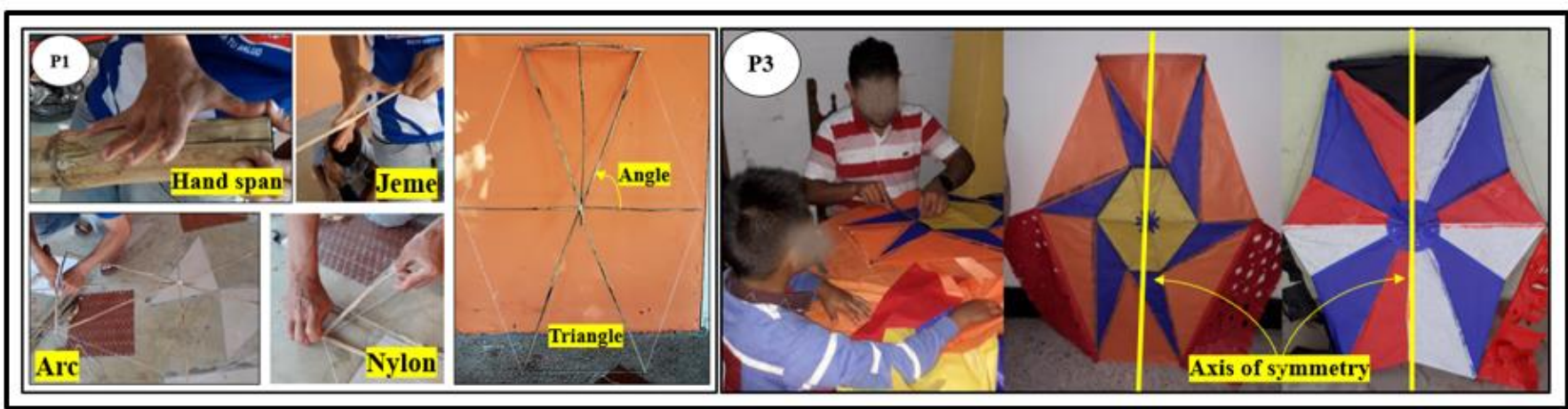

Figure 3. Making of the kites by P1 and P3

external connections from an ethnomathematical perspective.

Next, the results are presented that refer to the empirical phenomenon associated with the daily practices explored from an integrated vision that includes ethnomathematics, STEAM education, and the globalized approach to show the mathematical connections. We also recognize that the following section is a broad sample local integration achieved from develop the four pair of networking strategies.

\section{RESULTS: DAILY PRACTICES FROM AN INTEGRATED VISION OF THE THREE THEORETICAL APPROACHES}

\section{Kite Making}

In this first practice, two Colombian artisans, P1 and P3 participate, called kite makers (person who makes kites), who make this artefact for fun or as a game for people of different ages. From the ethnomathematics perspective, it should be noted that both participants make the kite following five moments with either wild cane or guadua (also known as Colombian bamboo), which they measure with non-conventional units of measurement, the handspan and the jeme to know the size (first moment) and obtain the three rods of a normal kite or the five ribs of a bow kite (second moment). Subsequently, the rods are tied with a cord, nylon or string considering the centre of the rods that allude to the symmetry of the kite (third moment). Then, the kite makers verify the structure of the kite with a cord that acts as a measurement pattern (fourth moment). The structure of the kite, or skeleton, is lined with paper or plastic, considering the number of sheets that depend on the size of the kite (fifth moment). In this context, delving into the structure of the kite, materials for its elaboration and the role it plays in the teaching and learning of mathematics and other branches of science, we find that the National Aeronautics and Space Administration (NASA, 2016) affirms that

"there are many types of kites, and over the years the materials used to build kites have changed.
Materials have included silk, bamboo, string, plastic, nylon, wood and more. NASA has classified five different types of kites. Reviewing the different kites will help you as the teacher and will help prepare your students for this lesson. The five types of kites discussed in this lesson are the Winged Box, the Sled, the Delta, the Box Kite, and finally, the Diamond (p. 5)."

From the point of view of STEAM education, in the development of kites, in addition to mathematical knowledge (Figure 3), knowledge of technology and art are used. In Figure 3, it is observed that for the design of the kites, geometric figures such as scalene triangles, isosceles triangles, rhombuses, hexagons, stars of different-numbered points, squares, and rectangles are considered, depending on the creativity of the kite maker. For example, P1 only made the structure of the comet, while P3 makes fan and star shapes, which are made up of triangles and hexagons, and the symmetrical line is observed in the centre of the kite. In the kite, there are opposite angles by the vertex, complementary, supplementary, among others. In the making of kites, as has been indicated, technology also intervenes, which is a human activity to solve problems or to satisfy needs at a certain moment. For this, most of the time artefacts are created; objects such as pots, furniture, dresses, cars, cell phones (smartphones), televisions, robots, computers. That is, all of man's creation with scientific knowledge is technology. Additionally, as indicated, art is also present, since it is evident that the visual result of the kite depends, to a large extent, on the creativity of the kite maker. These artefacts attract the attention of children of different ages and adults (Figure 4), so that in the classroom, the kite can be a motivating object useful for, from a globalized approach, connecting mathematics with one's own culture and with the reality that surrounds us.

In geometry classes, it is important for the mathematics teacher to develop activities directed towards the construction of different types of kites since it would be in accordance with the objectives set by the NCTM (2000) when it states that 


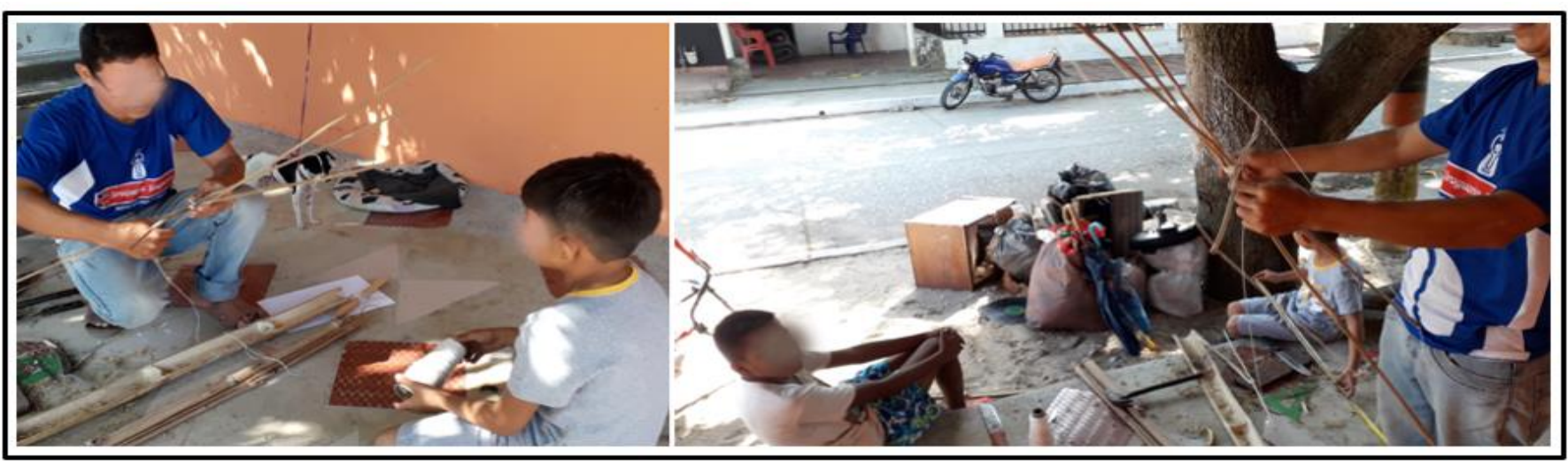

Figure 4 . The kite is an artefact that captures the attention of children

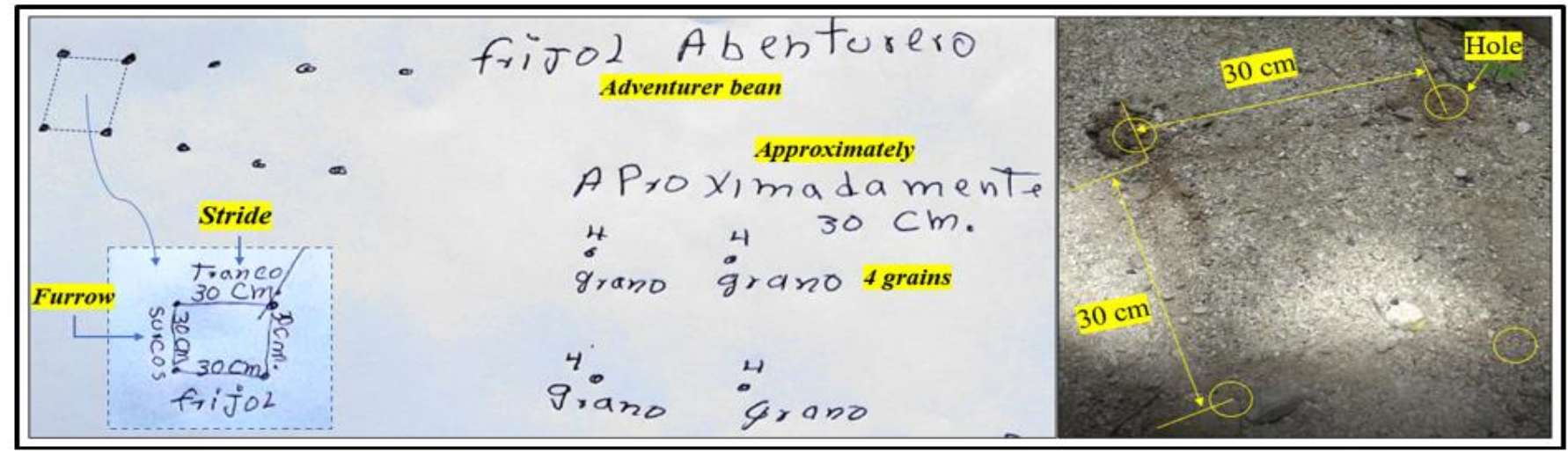

Figure 5. Bean-planting method of P2

\begin{abstract}
"students can measure the angles of the triangles in the kite and see that their corresponding angles are congruent. They can measure the lengths of the sides of the triangles and see that the differences are not constant but are instead related by a constant scale factor. With the teacher's guidance, students can thus begin to develop a more formal definition of similarity in terms of relationships among sides and angles (p. 234)."
\end{abstract}

On the other hand, we consider relevant the development of kites and their insertion into the mathematics classroom, among other science classrooms, because "students will learn about motions and forces, transfer of energy, abilities of technological design, energy in the earth system, science as a human endeavor, and historical perspectives as they create their own kites" (NASA, 2016, p. 2). In fact, one of NASA's main goals is for students to develop an understanding of mathematical and geometric terms and concepts and use them to build kites. For example, the activity of flying kites is a benefit for students to acquire the idea of aerodynamic forces.

\section{Agriculture and Commercialisation of Corn, Coffee, and Beans}

Agriculture is a common daily practice around the world. In this research, we consider a farmer (P2) who sows corn, coffee, and beans in the Mexican context. An approach from the ethnomathematics perspective shows that P2 considers non-conventional measures, such as the step or the rod to measure the terrain and calculate the distance between the plants. In his speech, he always mentioned that ten thousand corn plants fit on one hectare of land. However, P2 differentiates the three types of sowing, mentioning characteristics according to the measurements, for example, beans are sown $30 \mathrm{~cm}$ apart between plants, corn is sown 1 meter $(m)$ apart, and coffee is sown $6 \mathrm{~m}$ away. He affirmed that the step is equivalent to $70 \mathrm{~cm}$ and to complete the meter, he estimates $30 \mathrm{~cm}$ with the lance with which he makes the hole to cast the seed, that is, $70 \mathrm{~cm}+30 \mathrm{~cm}=100 \mathrm{~cm}=1 \mathrm{~m}$. Another equivalence that he established was that the rod or stick equivalent to the measurement from the feet to the belt or strap, equivalent to the measurement from the tip of the finger to the centre of the chest, is equal to one meter. For the commercialization of the product, P2 uses units of measure of capacities such as the sack or bag, a can to measure coffee, a large liter, a small liter, a quintal, and a bushel (almud). From a STEAM approach, agronomy or agriculture is in charge of studying the work in the field such as sowing, in which mathematical knowledge is used to favour the growth of trees or plants, the distribution of nutrients between plants planted by squares, the cleaning of the furrows, and the farmer's own walking. In Figure 5, the division of the 


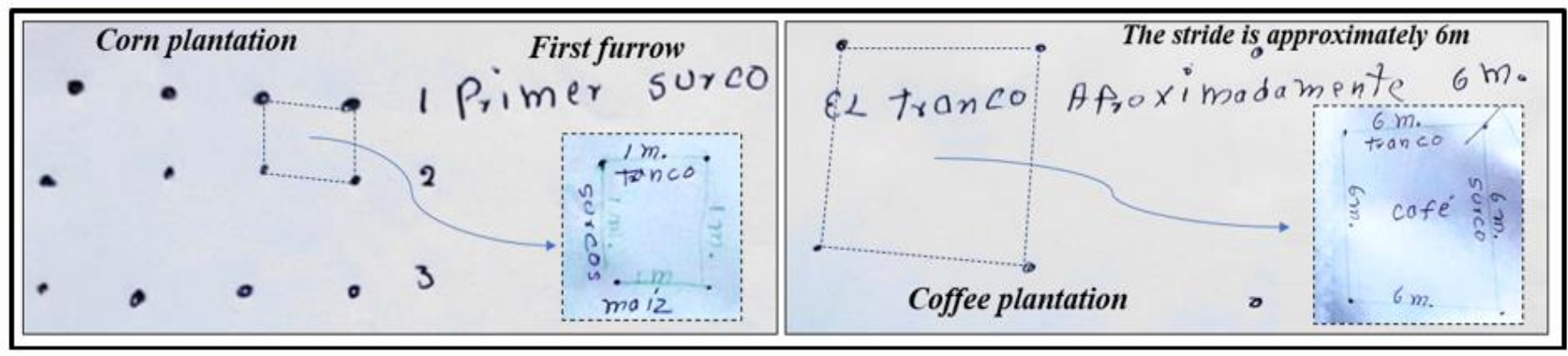

Figure 6. Corn and coffee-planting method of P2

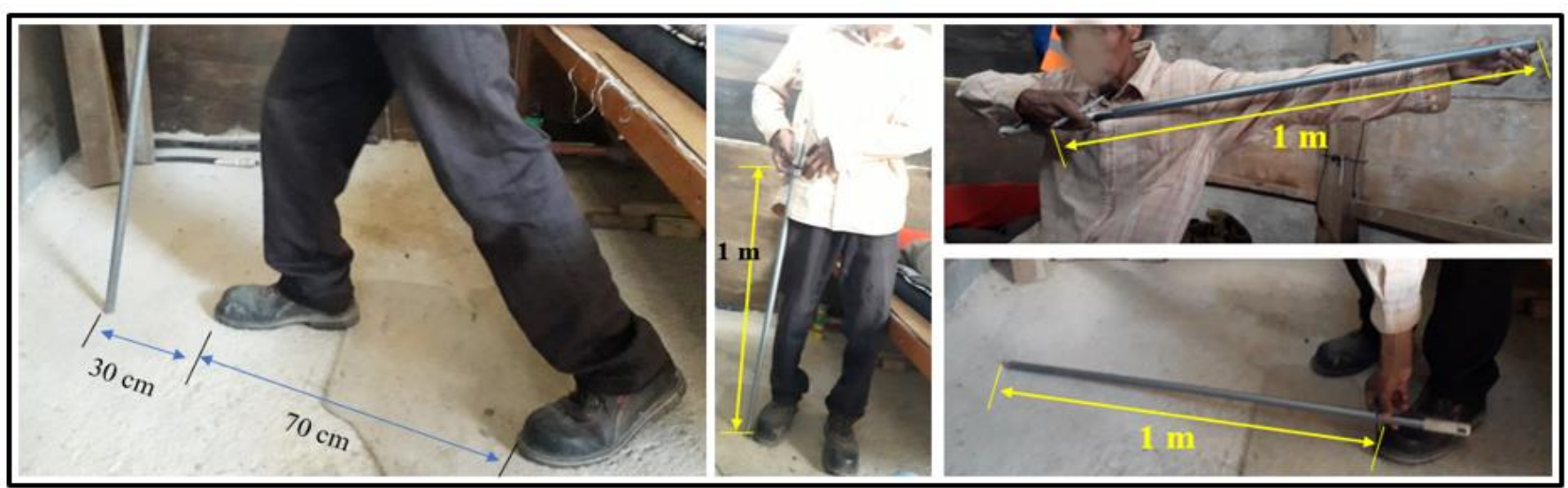

Figure 7. Non-conventional measurements that are equivalent to one meter

land in the bean planting is presented wherein each hole they put four grains as a counting activity.

Figure 6 shows the conventional and nonconventional measurements used by $\mathrm{P} 2$ in the planting of corn and coffee, to determine the distance between rows and considering the fundamental requirements for plant growth.

The measurements of the terrain are given by the recursion and creativity of P2 when using the different parts of his body. For example, measurements such as the step plus $30 \mathrm{~cm}$, the length from the tips of the fingers to the centre of the chest, the length from the feet to the belt and the wood stick, are equivalent to 1 meter (see Figure 7). In these measurement processes, agricultural science is integrated with mathematics, specifically with the metric systems that are part of the curriculum at the different school levels (Figure 7). Additionally, for the commercialisation of the harvested products, containers are used that can contribute to the teaching process of capacity measurements and geometric notions such as the cylinder, the circumference, the circle, and other mathematical processes involved in the use of arithmetic operations that trigger measurement (NCTM, 2000).

Next, Figure 8 shows equivalences, conversions between capacity measures, where P2 proposes and adequately solves mathematical situations from a cultural perspective. The measuring processes carried out by the farmer are typical of land surveying as a science in charge of measuring and delimiting land, where we highlight the mathematical potential essential to carry out daily practices related to the planting of coffee, beans, and corn. In this scenario, talking about STEAM and, more particularly, about the connections between mathematics and science, is to refer to the connections with real life, with the environment since in fact in agriculture, elements of chemistry, physics, biology, fertilizers, climatic, and meteorological effects can also be considered, therefore, it is consistent with the ethnomathematical bases to bring this knowledge in an integrated way into the classroom.

In addition to these connections with the environment, Figure 9 shows that the farmer makes intradisciplinary (internal) mathematical connections to find the equivalences between units of measure of capacity (liter, sack) and mass (kilogram). Also, other mathematical aspects integrated into these connections are recognised, such as numerical operations (addition and multiplication), geometric figures such as the cylinder (liter), their graphic representations and the counting processes as suggested by the NCTM (2000). Generally, these types of ethnomathematical connections are at the same time globalized (Alsina, 2012) since they relate mathematics to the sociocultural context (in this specific case, of the farmer). It is reflected that this type of explored knowledge contributes to the teaching and learning processes of measuring systems. In fact, from ethnomathematics, the explored connections are internal and external at the same time (Rodríguez-Nieto, 2020), since different practices or types of plantations are externally connected that use the 


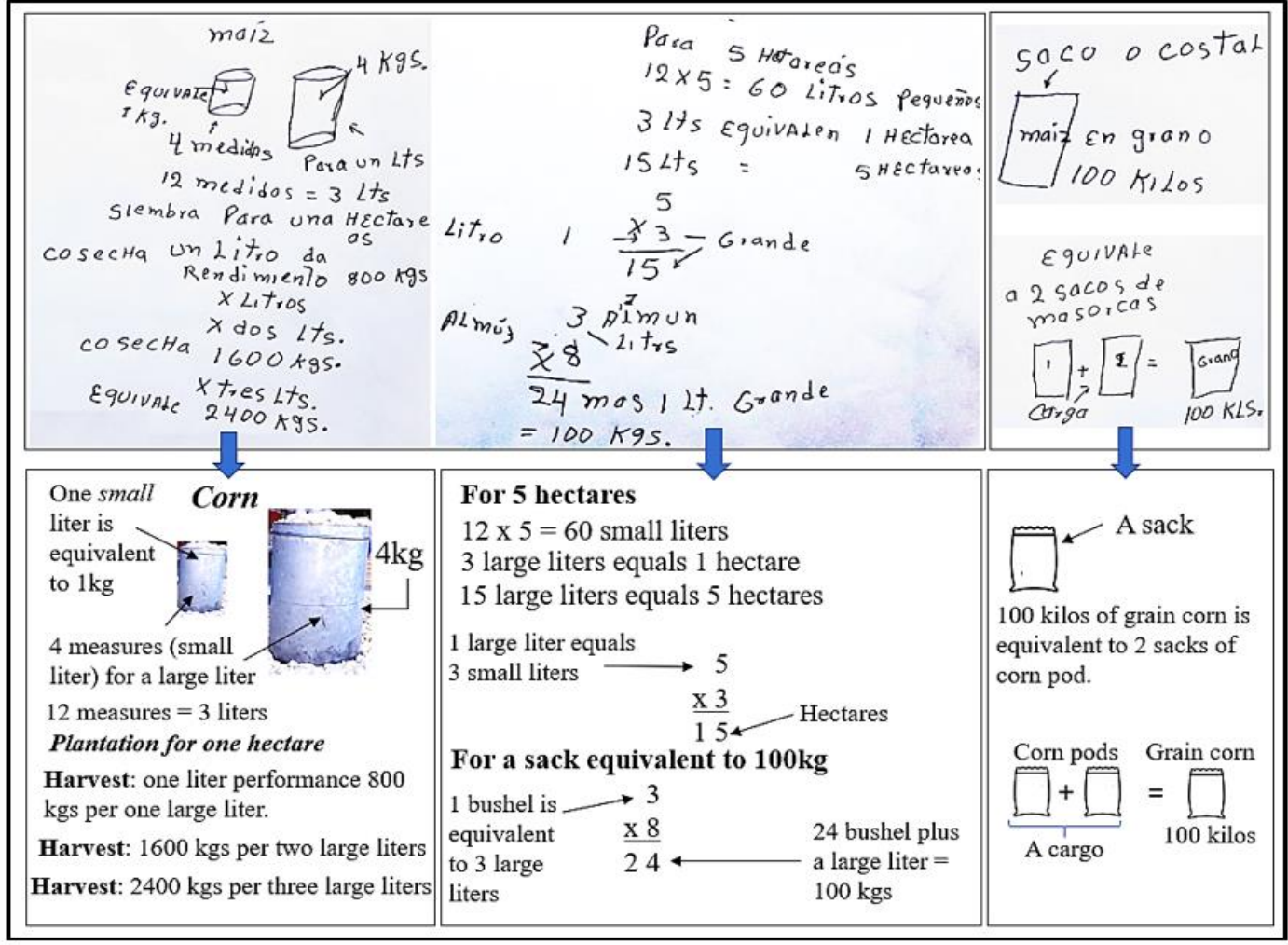

Figure 8. Mathematical procedures performed by P2 using capacity measurements

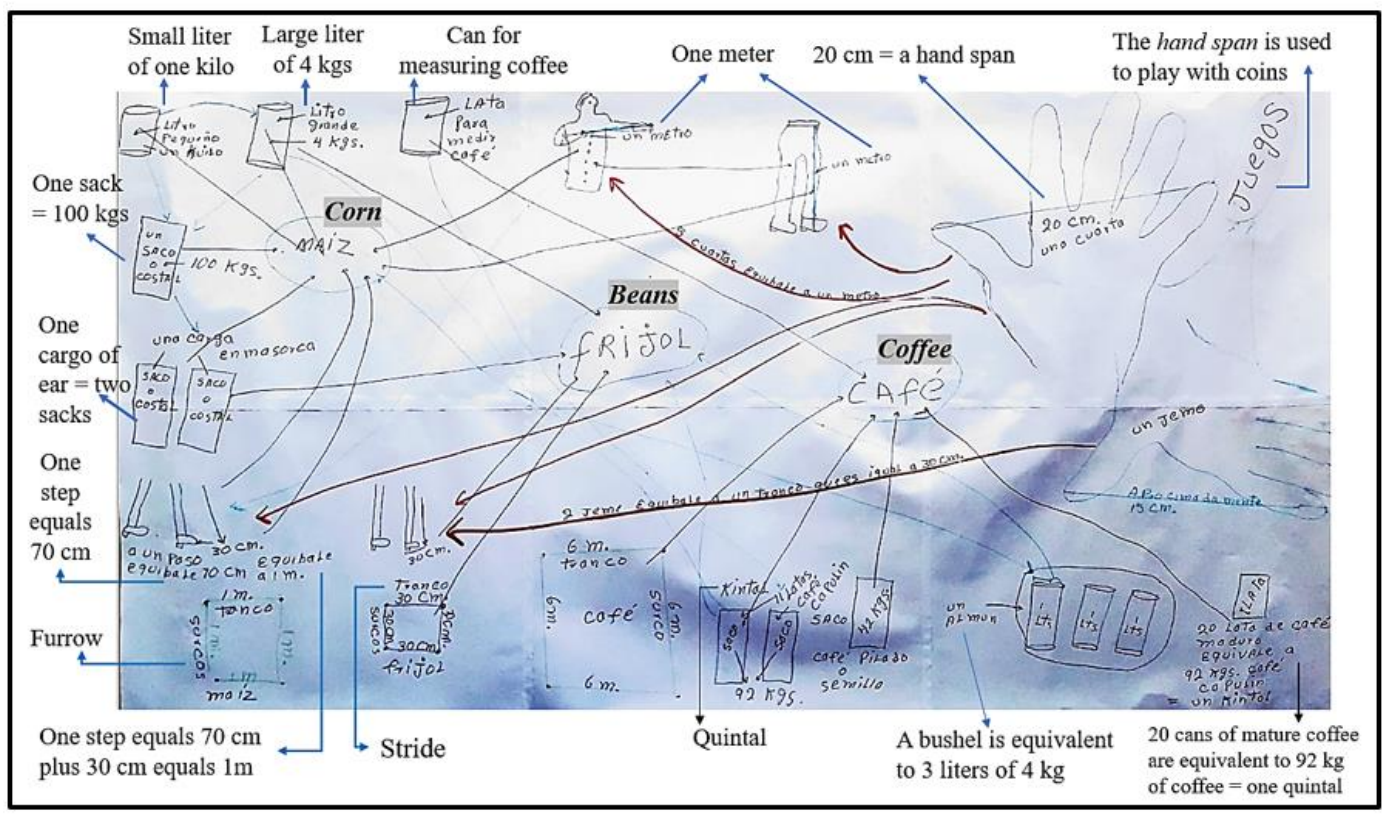

Figure 9. Intradisciplinary connections between units of measurement used by P2

unit of measurement 'the liter', which is activated by the same P2 who establishes the internal connection in each practice.

When P2 uses the unit of measurement "the sack" in the same way in the three different daily practices (corn, bean, and coffee sowing), the internal and external connections are activated simultaneously because P2 is the same one that performs the different practices (connection diagram in Figure 10).
Furthermore, Figure 10 shows that P2 uses the hand span measurement when playing with a coin, where the game rules are as follows: Player 1 throws a coin and player 2 throws another coin, and if it falls next to the first coin at a hand span distance, then player 2 wins the first coin. This refers to the fact that P2 when developing the activity of playing relates other universal activities such as measuring (in a non-conventional way) and counting coins in Mexican Pesos. Figure 10 shows internal and external connections established by P2, 


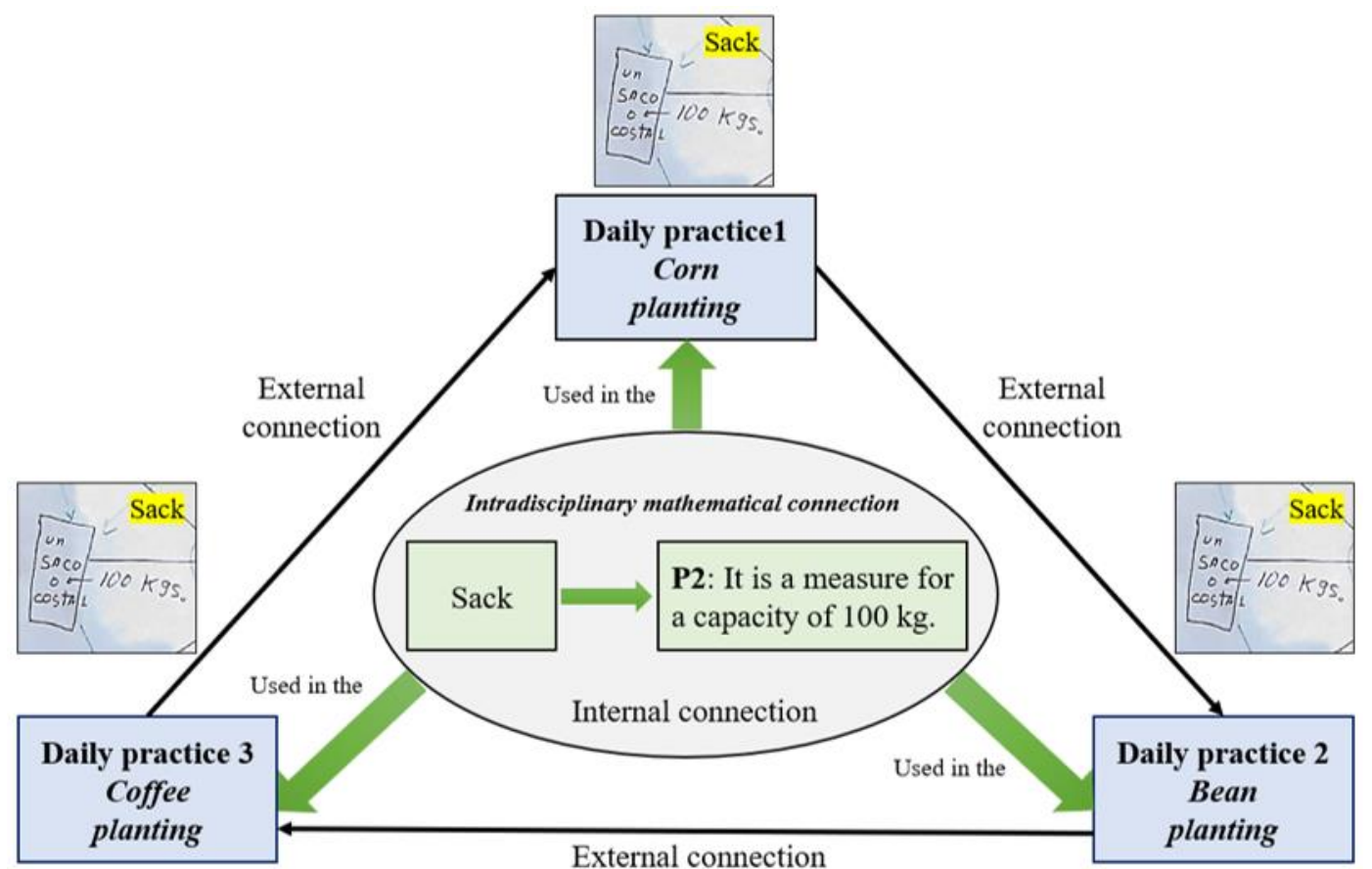

Figure 10. Internal and external connection established by P2

since it uses the unit of measure "the sack" in different daily practices in which differences are found, such as the distances between plants due to their size and growth.

\section{Making of Cabinets and Masks}

In marketplaces, various objects or containers are used as units of measurement of capacity. For example, wooden boxes, tanks, cans, or sacks, among others. In particular, the wooden box is used to market tomatoes, melons, and mangoes with a capacity of 30 kilograms. The reality is that some people dispose of them and throw them away without giving them proper use. However, based on an analysis from the ethnomathematics perspective, P3 values and recycles wooden boxes and, with his creativity, builds cabinets or closets, tables, among other engineering works to place clothes, basic groceries, or cosmetics and beauty products. In this work, P3 uses measuring instruments such as the metre, the square, and tries to make the furniture symmetrical. The boxes could be used to find the volume and its total area, etc.

From a STEAM perspective, math, engineering, and art skills are integrated. These disciplines are related because mathematics arises to solve real-life problems and for this, various artefacts, formulas, recipes, laws, rules, among other things, were created, which, in fact, are works of engineering and artistic works at the same time: when human beings make an artistic work, in addition to considering engineering knowledge, they follow mathematical processes and activities such as measuring, counting, estimating, exploring symmetries, calculating, based on basic arithmetic operations, etc. For example, create patterns like in the case of dressmakers, use the square like carpenters. Delving into the relationship between mathematics and art, Wagner and Flores (2020) state that:
when seeing, speaking, and imagining mathematics in art, a way of understanding mathematics emerges, appears, is shown and throbs in the interaction between images and looks. When you see, speak, and imagine mathematics in art, it is a way of understanding mathematics that comes to life through what you say, what you see, what you imagine is palpitating: "both looking at art, you see mathematics and how to use mathematics to make art" (p. 11).

Specifically, in this daily practice, we identify the relationship between art, mathematics and culture that was explored through ethnomathematics, which values the art of cultural groups (Aroca, 2016; D'Ambrosio, 1995, 2001, 2014). In fact, the undervaluation of the wooden box is faced by some people, however, there are other people like $\mathrm{P} 3$ that recycles them and uses them to make cabinets or closets destined to satisfy a human need (see Figure 11).

From the point of view of a STEAM project, the teacher asking the students to make a closet or other object with recyclable material could be a success, for example, to improve the understanding of the notions of measuring, counting, symmetry, angle, area, perimeter, volume, parallelism, perpendicularity, and other activities such as estimating the amount of paint and the mixture of colours, counting pieces or material, among others, in addition to integrating engineering knowledge such as balance so that cabinets and dressers are maintained standing. From a globalized approach, Figure 


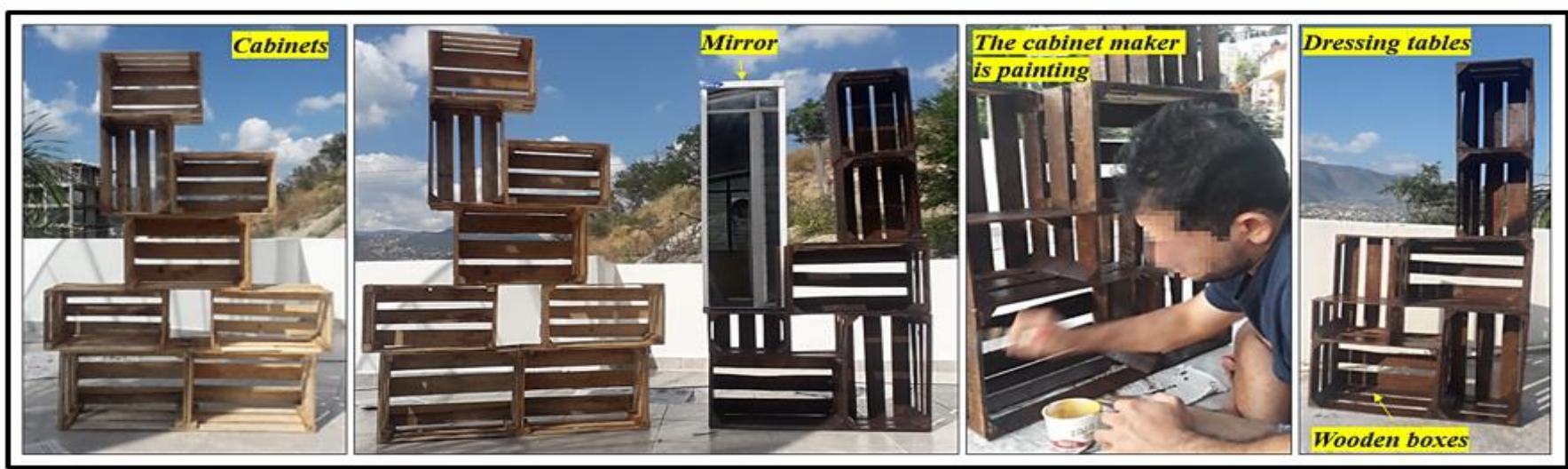

Figure 11. Creation of cabinets and dressing tables by P3
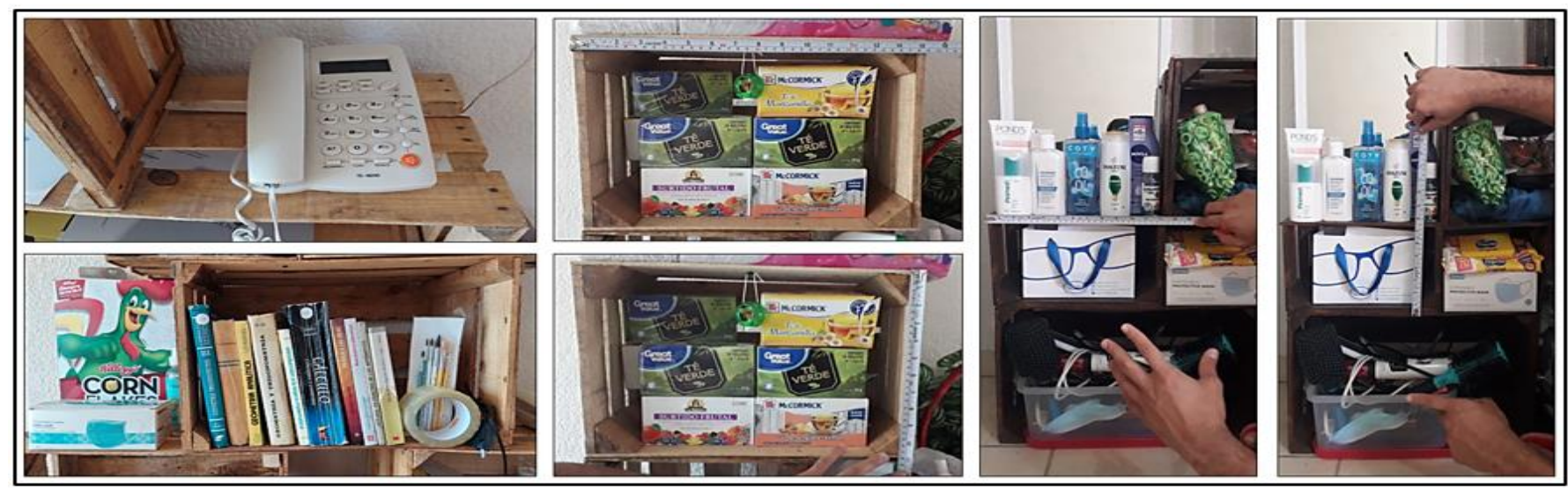

Figure 12. Use of cabinet and dressing table made by P3

12 shows a type of use of the cabinets, to place nonperishable products from the family basket (groceries), medicine boxes, ornaments, books, and, especially on the dressing table, hairdressing items, cosmetics, shampoo, body creams, makeup, perfumes, among other objects are placed, which is evidence of the connections of this type of daily practice with the social environment.

In this line of integration between art and mathematics in a STEAM framework, P3 also makes masks that are used during the Carnival of Barranquilla (Colombia), which is also another clear evidence of connection with the social and cultural environment, from a globalized approach. Generally, the masks are made with clay and paper moulds, as evidenced in Paternina-Borja et al. (2020), who investigated the bull's mask. However, in this research the production of this daily practice is expanded since $\mathrm{P} 3$ made 1) marimonda, 2) gorilla, and 3) congo masks (Figure 13), out of recyclable paper, garbage bags, tape, glue, scissors, cardboard boxes, wood, and vinyl, implicitly showing mathematical concepts such as symmetry and measurements. It is noted that the marimonda mask was made for a fair about mathematical creativity and therefore, art was mixed with mathematics, resulting in the mathematical marimonda, made with a box (rectangular prism), decorated with triangles on the face and ears filled with circles and triangles.
In Figure 14, the gorilla and congo masks were a challenging job for $\mathrm{P} 3$, as he had to retain symmetry in the face moulded from wet notebook paper and liquid glue. The mathematical congo is a work of art allusive to the Barranquilla carnival, which generally in the headdress, coloured flowers are placed, but in this case, geometric figures such as the triangle, square, circle, rectangle, concentric circumferences, trapezoids were placed, as well as rhombuses, the Archimedean spiral, a cylinder such as a toilet paper carton, a prism (medicine box), a parallelepiped (perfume box), a sphere, a truncated cone, etc.

\section{Masonry and Construction of Buildings}

Masonry is a daily practice characterised as the art of the construction of houses and buildings. From the ethnomathematical perspective, P4 makes constructions and states that he uses mathematics to interpret and measure the plans supplied by an architect or civil engineer, recognise the types of scales (extension and reduction), measure the tie beams. For example, in each tie, the rods form a square $20 \mathrm{~cm}$ long by $20 \mathrm{~cm}$ wide. Also, he uses mathematics to create a budget for the material to be used for a job considering the basic operations of arithmetic, uses the inch to classify the rods, the square to measure angles, considers the package with a capacity of 50 kilograms of cement and 


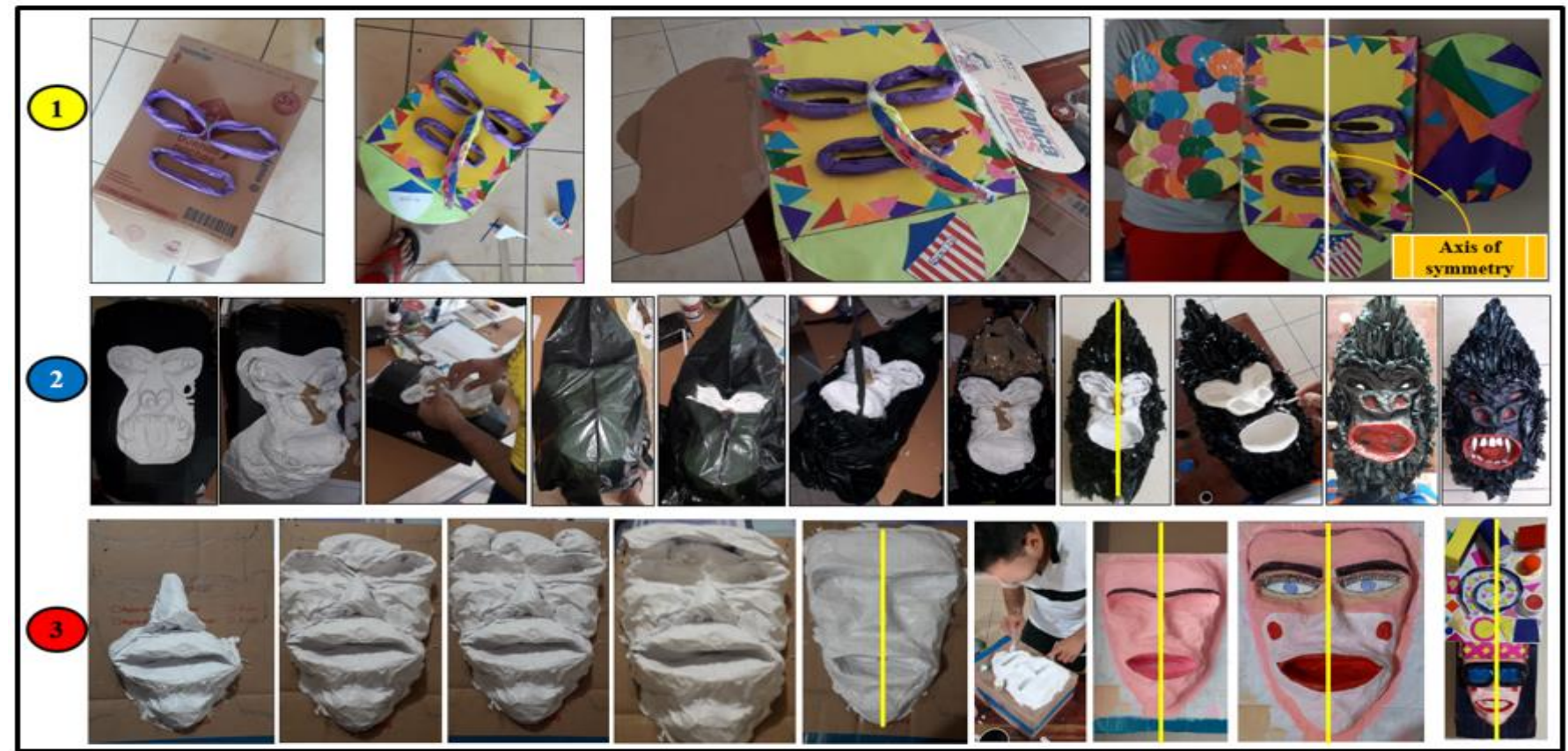

Figure 13. Marimonda, gorilla, and congo masks

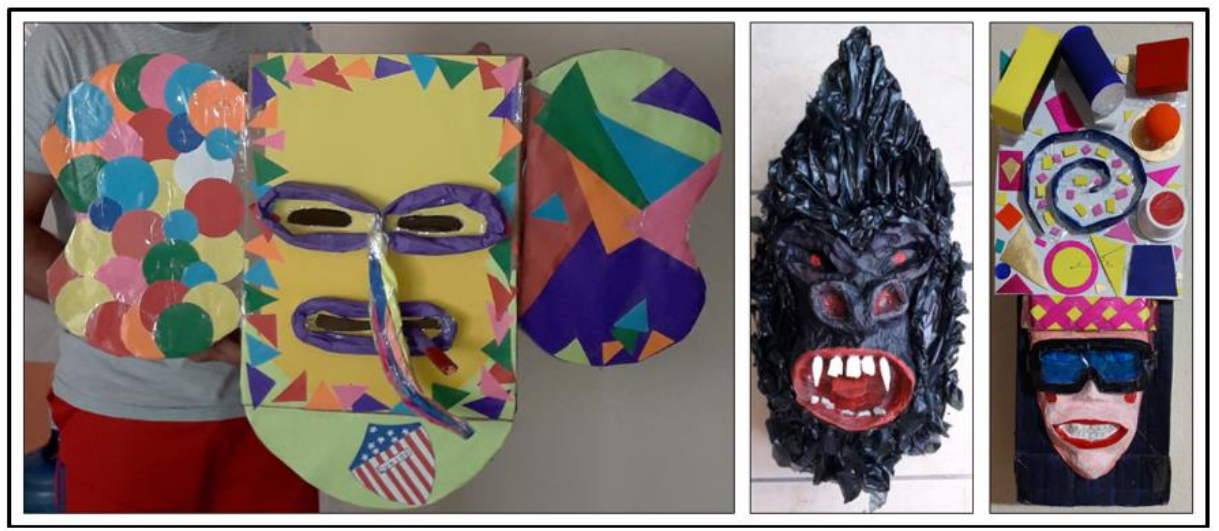

Figure 14. Three masks, three experiences of connections between art and mathematics

the bucket with a capacity of 19 liters of water. In addition, it mentions words like slope to refer to the inclination or level of a piece or floor with respect to a reference point. Other mathematics is evidenced in the shapes of the houses, buildings, and facades that the masons make.

From the integrated STEAM approach, P4 constantly connects the knowledge of engineering and mathematics: he reads architectural plans, interpreting the measurements of different scales for the construction of a building, for example, in this case, he handles the scale 1:100 (one unit on the plane it represents, one hundred units in reality). Also, the measurements of the $3 / 8,1 / 2$ and one-inch rods, which are useful for the elaboration of footings or templates (superficial foundations). The steel grid on the construction is made up of crossed rods that form squares with four $90^{\circ}$ angles and each one has an area of $400 \mathrm{~cm}^{2}$, that is, their sides measure $20 \mathrm{~cm}$ each. Likewise, P4 uses a level and measurements to find the slope, unevenness, or inclination that the floor will have and for good drainage, and the vertical and horizontal beams are attached to this steel grid (Figure 15).

In Figure 15, P4 is working on the elaboration of a five-metre-deep water well in a cylindrical shape and its thickness is delimited by two frameworks with an internal diameter of $1.50 \mathrm{~m}$ and an exterior diameter of $1.80 \mathrm{~m}$, and a steel lattice (with squares $15 \mathrm{~cm}$ long and wide) in the middle of the frameworks (two rings can be seen in Figure 15) to strengthen the cementitious concrete. From the STEAM perspective, the works made by $\mathrm{P} 4$ are engineering and are important to take them to the classroom. The student may not be able to make a construction like those presented in Figure 15 and Figure 16 , but could make models with measurements on the reduction scales that represent reality, developing their art skills and techniques for the invention of artefacts. 


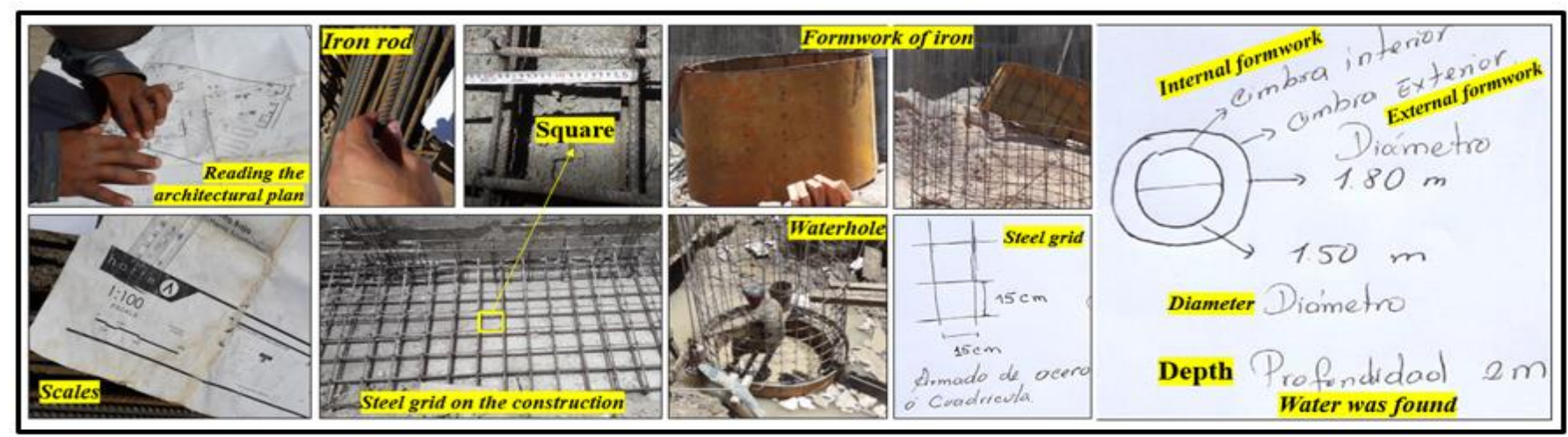

Figure 15. Used by the mason in the construction of buildings

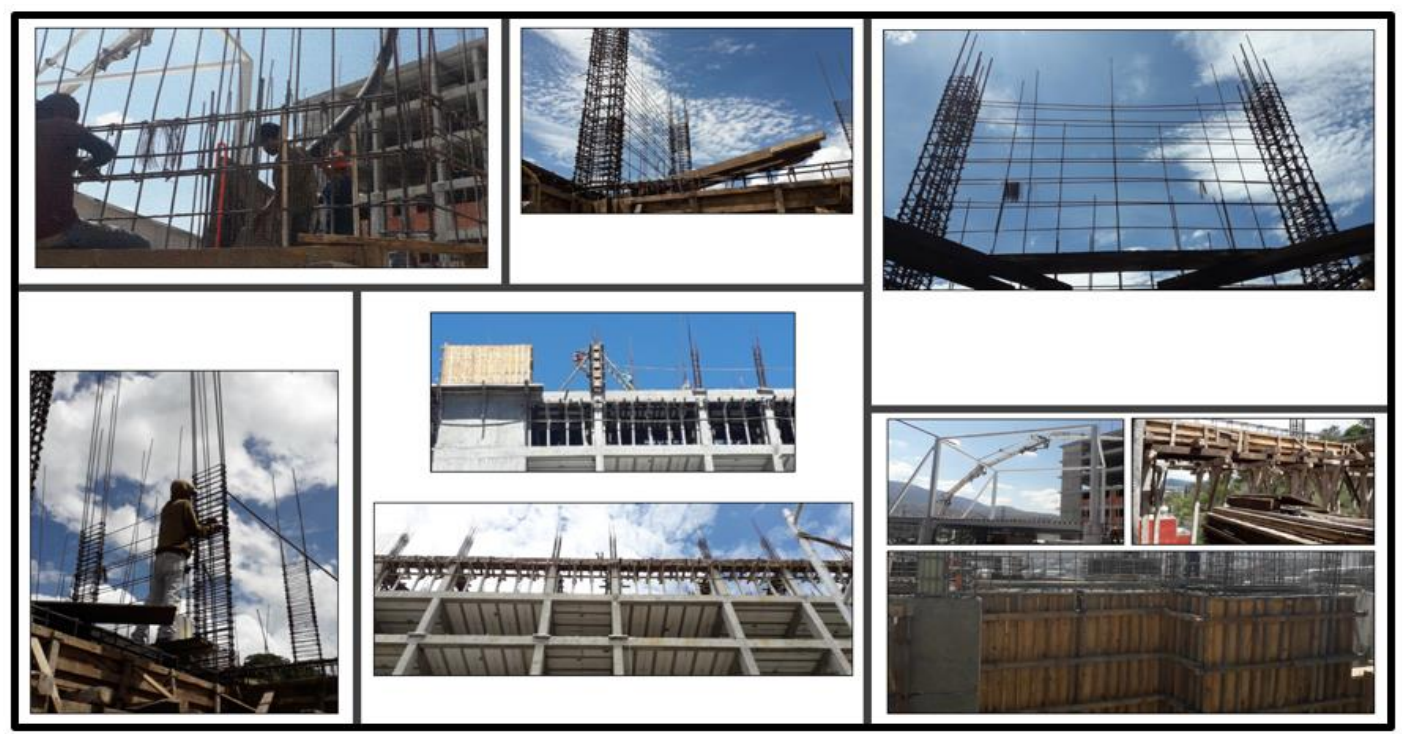

Figure 16. Photographs of buildings of civil engineering work

\section{Making of Box Kites}

For the making of box kites, and carrying out an analysis from the ethnomathematics perspective, P5 follows six moments. First, he measures the guadua bamboo with the metre or 'by eye' to get a rod and then obtain the other rods using the first as a measurement pattern until you get six rods. When P5 mentioned the term 'by eye', he referred to a measurement of approximately $80 \mathrm{~cm}$ and pointed out that it is equivalent to the measurement from the feet to below the navel, since, from the feet to the height of the navel, it is one meter. In the second moment, he used the 'bamboo stick' measurement pattern to make the squares where the rods are held, four long rods forming a parallelepiped. Third, the two remaining long rods intersect forming a square with four $90^{\circ}$ angles, which is tied with a string in the centre of the rods that formed the parallelepiped (fourth moment). In the fifth moment, P5 joins the ends of the square with the ends of the parallelepiped to give consistency to the structure of the box. In the sixth moment, it is lined with paper and thus P5 was able to distinguish the squares, rectangles, right triangles, and as researchers, we distinguished the trapezoids formed on the outside of this artefact (more detailed information in Rodríguez-Nieto, 2020).

From STEAM education, geometric notions such as the segment, the rectangle, the triangle, the trapezium, the square, and the parallelepiped can be identified, where the areas of the plane figures, the core areas, the volume of the three-dimensional figure, measurement of segments, types of angles, symmetries, parallel and perpendicular lines, perimeter can be found that can be problematized in the classroom like the kite (Figure 17). For example, P5 in the following interview excerpt evidences some mathematical concepts:

P5: This must measure ninety degrees because this is a right angle from here to here. The white paper one is a triangle, you see it, it has three sides, one, two and three (points at them with his finger), this is another triangle with three sides (blue) and if you take it whole it is also a triangle.

I: Here (points to the vertex of the right angle) What happens? 


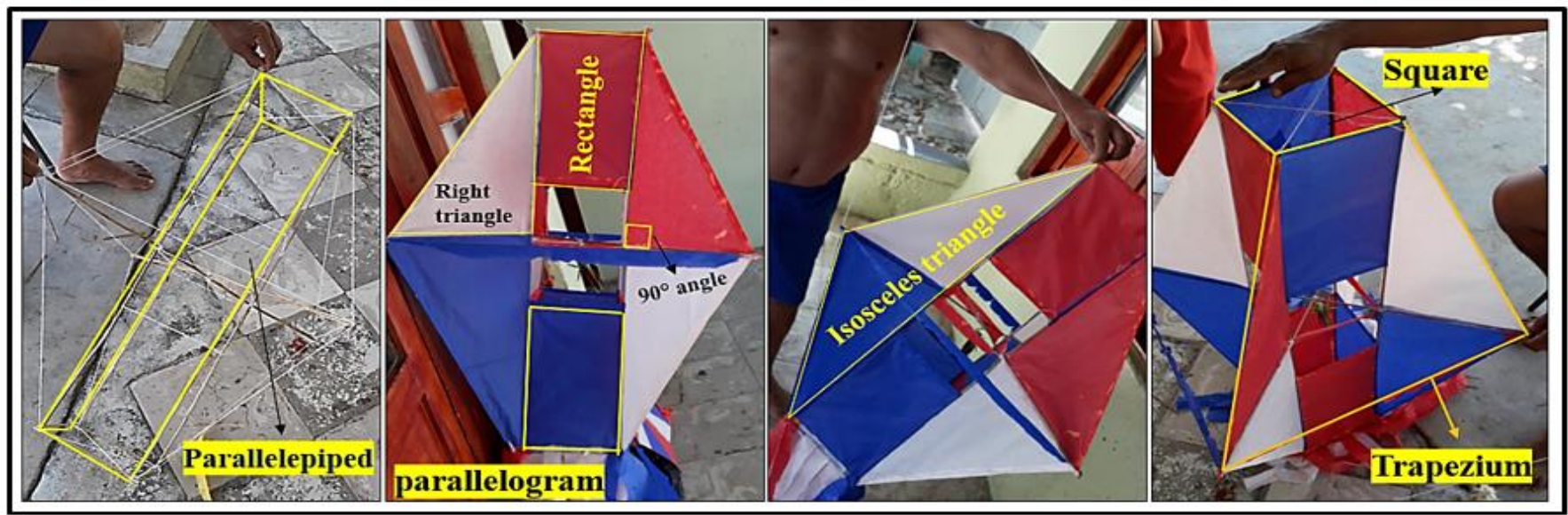

Figure 17. Mathematics immersed in the box kite and a child interested in the artefact

P5: Here it must be straight, right angle, where the two rods meet, it must be straight, you put a square here and it must be straight.

\section{I: Right angle. What do you mean?}

P5: That this rod is not going to be up or down, it must be straight.

I: And when you refer to a right triangle, what do you mean?

P5: That is, the shape, it has a mathematical shape that ..., for example, this is a triangle, up here this is a square, the first thing that is assembled is the rectangle, which are the four rods (...), this here forms a right angle, I put the square here ...

\section{I: How much angle?}

P5: Ninety, the angle is right.

I: Approximately, how long does it take you to make a drawer?

\section{P5: Lined and all, three hours.}

Similarly, to the kite, in the making of the box kite the knowledge of technology and artistic interventions was evidenced; design of the kite, creativity in dicho design, etc. And, again, a clear connection is established with the cultural environment and that this artifact is deeply rooted in Colombian culture as an element of entertainment. Therefore, taking advantage of this type of situation in the classroom offers this globalizing approach in which, in addition to integrating knowledge of different natures, it is linked to mathematical knowledge with reality. In this research two types of kites are shown: one hexagonal and another like the box suggested by NASA (2016), which could continue to be analysed in detail in future research for other fields of science such as physics and aerodynamics.

\section{DISCUSSION AND FINAL REFLECTIONS}

An integrated view of ethnomathematics, STEAM education, and the globalized approach have been presented to analyse mathematical connections in daily practices, as these theoretical approaches consider it important to recognise the mathematics practiced by cultural groups, in connection with other disciplines and with the environment. It is considered that each of the disciplines can contribute elements that serve to enrich the analysis of daily practices and, thus, to better understand the connections of different nature that are established in these practices. It should be noted that the networking developed, values the possibility of making more detailed analyses of the mathematical connections made by cultural groups in different daily practices, unlike other theoretical networks that have been focused on argumentative grammar (Tabach et al., 2020), focused on delving deeper into the notion of the mathematical object (Font et al., 2016), or on detailing the notion of mathematical connection as the tip of an iceberg made up of a conglomerate of practices, processes, objects and semiotic functions that relate them (Rodríguez-Nieto et al., 2021b).

This integrated approach has a twofold purpose: on the one hand, from a literacy perspective, contemporary curriculum guidelines encourage the connection between knowledge. Thus, as indicated, the NCTM (2000) stresses that mathematical connections promote understanding. In this sense, "school mathematical experiences at all levels should include opportunities to learn by working on problems arising in contexts outside of mathematics. These connections can be to other subject areas and disciplines as well as to students' daily lives" (NCTM, 2000, p. 65-66); on the other hand, it is necessary to exemplify these practices and their analysis so that teachers can implement similar activities in the classroom and, in this way, foster intra-disciplinary connections, which allow mathematics to be presented as an integrated whole, rather than as a set of isolated knowledge; interdisciplinary connections, between 
knowledge from different disciplines that feed each other: mathematics with science, technology, engineering and art; and connections between the mathematics practised by cultural groups with institutionalised mathematics, which are some of the key aspects provided by ethnomathematics, STEAM education, and the globalized approach.

From this point of view, our research has sought to extend previous attempts to articulate some of these theories, such as the study by Rosa and Orey (2021), where they approached an ethnomathematical perspective of the STEM approach with different examples. In our case, the connections that emerge in various daily practices from the articulation between ethnomathematics, STEAM education, and the globalized approach have been analyzed so that, based on the joint analysis of the role of culture, interdisciplinarity and the understanding of reality, the current understanding about the role of mathematics and its use can be improved.

The main limitation of the study is that, as a consequence of the type of practices analyzed, it has not been possible to inquire about the implementation of these connections in teaching practices in the school context, despite the fact that in recent years some curricula have already started to suggest, for example, that "using mathematics" is one of the three crosscurricular skills at the heart of the curriculum. It is the skill of applying mathematical concepts, processes and understanding appropriately in different contexts. Ideally, teachers will use relevant, real-life situations that require mathematical thinking (Council for the Curriculum, Examinations \& Assessment-CCEA, 2020). From this perspective, in the future it will be necessary to continue deepening these connections, while specific guidelines must be provided to teachers to promote them within the framework of the teaching practices they carry out.

Author contributions: All authors have sufficiently contributed to the study, and agreed with the results and conclusions.

Funding: This Research has received external funding from the M. A. Canals Chair of Mathematics Education at the University of Girona.

Declaration of interest: No conflict of interest is declared by authors.

\section{REFERENCES}

Alsina, Á. (2012). Hacia un enfoque globalizado de la educación matemática en las primeras edades [Towards a globalized approach to mathematics education in early ages]. Números [Numbers], 80, 724.

Alsina, Á. (2014). Procesos matemáticos en Educación Infantil: 50 ideas clave [Mathematical processes in Early Childhood Education: 50 key ideas]. Números [Numbers], 86(12), 5-28.
Alsina, Á. (2020). Conexiones matemáticas a través de actividades STEAM en Educación Infantil [Mathematical connections through STEAM activities in Early Childhood Education]. UNIÓNRevista Iberoamericana de Educación Matemática [UNION-Ibero-American Journal of Mathematics Education], 16(58), 168-190.

Aroca, A. (2016). La definición etimológica de etnomatemática e implicaciones en educación matemática [The etymological definition of ethnomathematics and implications in mathematics education]. Educación Matemática [Mathematics Education], 28(2), 175-195. https:// doi.org/10.24844/EM2802.07

Artigue, M., \& Mariotti, M. (2014). Networking theoretical frames: The ReMath enterprise. Educational Studies in Mathematics, 85(3), 329-355. https:// doi.org/10.1007/s10649-013-9522-2

Balka, D. (2011). Standards of mathematical practice and STEM. Math-science connector newsletter (pp. 6-8). School Science and Mathematics Association. http:/ / ssma.play-cello.com/wp-content/ uploads/2016/02/MathScienceConnectorsummer2011.pdf.

Belbase, S., Mainali, B., Kasemsukpipat, W., Tairab, H., Gochoo, M., \& Jarrah, A. (2021). At the dawn of science, technology, engineering, arts, and mathematics (STEAM) education: Prospects, priorities, processes, and problems. International Journal of Mathematical Education in Science and Technology, 1-37. https://doi.org/10.1080/ 0020739X.2021.1922943

Bikner-Ahsbahs, A., \& Prediger, S. (2010). Networking theories - an approach for exploiting the diversity of theoretical approaches. In B. Sriraman \& L. English (Eds.), Theories of mathematics education (Advances in mathematics education, pp. 589-592). Springer.

Bikner-Ahsbahs, A., \& Vohns, A. (2019). Theories of and in Mathematics Education. In Traditions in GermanSpeaking Mathematics Education Research (pp. 171200). Springer, Cham.

Bishop, A. (1999). Enculturación matemática. La educación matemática desde una perspectiva cultural [Mathematical enculturation. Mathematics education from a cultural perspective]. Paidós.

Braun, V., \& Clarke, V. (2006). Using thematic analysis in psychology. Qualitative Research in Psychology, 3(2), 77-101. https:/ / doi.org/10.1191/1478088706qp063oa

Castro, A., Rodríguez-Nieto, C. A., Aravena, L., Loncomilla, A., \& Pizarro, D. (2020). Nociones matemáticas evidenciadas en la práctica cotidiana de un carpintero del sur de Chile [Mathematical notions evidenced in the daily practice of a 
carpenter from south Chile]. Revista Científica [Scientific Journal], 39(3), 278-295. https:// doi.org/10.14483/23448350.16270

Chieus, G. (2009). A braça da rede, uma técnica Caiçara de medir [A braça da rede, a Caiçara measuring technique]. Revista Latinoamericana de Etnomatemática [Latin American Journal of Ethnomathematics], 2(2), 4-17.

Cohen, L., Manion, L., \& Morrison, K. (2018). Research methods in education. Routledge. https://doi.org/ 10.4324/9781315456539

Council for the Curriculum, Examinations \& Assessment-CCEA. (2020). Using mathematics. https://ccea.org.uk/foundation-stage/ curriculum/using-mathematics

Couso, D. (2017). Per a què estem a STEM? Un intent de definer l'alfabetització STEM per a tothom i amb valors [What are we at STEM for? An attempt to define STEM literacy for all and with values]. Ciències [Science], 34, 22-30. https://doi.org/ $10.5565 / \mathrm{rev} /$ ciencies. 403

D'Ambrosio, U. (1995). Multiculturalism and mathematics education. International Journal of Mathematical Education in Science and Technology, 26(3), 337-346. https:// doi.org/10.1080/002073995 0260304

D'Ambrosio, U. (2001). Etnomatemática: Elo entre las tradições e a modernidad. Colección: Tendencias en educación matemática [Ethnomathematics: Elo between traditions and modernity. Collection: Trends in Mathematics Education]. Autêtica [Authentic].

D'Ambrosio, U. (2007). The role of mathematics in educational systems. ZDM Mathematics Education, 39(1-2), 173-181. https://doi.org/10.1007/s11858006-0012-1

D’Ambrosio, U. (2014). Las bases conceptuales del programa etnomatemática [The conceptual foundations of the ethnomathematics program]. Revista Latinoamericana de Etnomatemática [Latin American Journal of Ethnomathematics], 7(2), 100-107.

D'Ambrosio, U. (2016). Polysemic interactions between ethnomathematics and culturally relevant pedagogy. In M. Rosa, U. D'Ambrosio, D. C. Orey, L. Shirley, W. V. Alangui, P. Palhares, \& M. E. Gavarrete (Eds.), An overview of the history of ethnomathematics (pp. 11-13). Springer.

D'Ambrosio, U., \& Knijnik, G. (2020). Encyclopedia of mathematics education. In S. Lerman (Ed.), Ethnomathematics (pp. 283-288). Springer. https:/ / doi.org/10.1007/978-3-030-15789-0_60

Delanty, G. (2000). Citizenship in a global age: Society, culture, politics. Open University Press.

Drijvers, P., Godino, J. D., Font, V., \& Trouche, L. (2013). One episode, two lenses. Educational Studies in
Mathematics, 82(1), 23-49. https:/ / doi.org/10.1007/ s10649-012-9416-8

European Communities. (2004). Europe needs more scientists. European Commission.

European Communities. (2007). Science education now: A renewed pedagogy for the future of Europe. European Commission.

Font, V., Trigueros, M., Badillo, E., \& Rubio, N. (2016). Mathematical objects through the lens of two different theoretical perspectives: APOS and OSA. Educational Studies in Mathematics, 91(1), 107-122. https:/ / doi.org/10.1007/s10649-015-9639-6

Freudenthal, H. (1991). Revisiting mathematics education. Kluwer Academic Publishers.

García-García, J., \& Bernandino-Silverio, N. (2019). Conocimientos geométricos en la elaboración de un artefacto en una Comunidad Nuu Savi [Geometric knowledge in the elaboration of an artifact in a Nuu Savi Community]. IE Revista de Investigación Educativa de la REDIECH [IE Journal of Educational Research of the REDIECH], 10(19), 105-120. https:/ / doi.org/10.33010/ie_rie_rediech.v10i19.634

García-García, J., \& Dolores-Flores, C. (2020). Exploring pre-university students' mathematical connections when solving calculus application problems. International Journal of Mathematical Education in Science and Technology, 52(6), 912-936. https:/ / doi.org/10.1080/0020739X.2020.1729429

Gerdes, P. (2013). Geometría y cestería de los Bora en la Amazonia Peruana [Geometry and basketry of the Bora in the Peruvian Amazon]. Ministerio de Educación [Ministry of Education].

Green, A. (1999). Education and globalization in Europe and East Asia: Convergent and divergent trends. Journal of Education Policy, 14(1), 55-71. https:/ / doi.org/10.1080/026809399286495

Lederman, L. (1998). ARISE: American renaissance in science education. Fermi National Accelerator Lab.

Longhurst, R. (2010). Semi-structured interviews and focus groups. In N. Clifford, S. French, \& G. Valentine (Eds.), Key methods in geography (pp. 103115). SAGE.

Ludeña, E. S. (2019). La educación STEAM y la cultura «maker» [STEAM education and the "maker" culture]. Padres y Maestros [Journal of Parents and Teachers], 379, 45-51. https://doi.org/10.14422/ pym.i379.y2019.008

Martín Carrasquilla, O. (2020). Las actitudes hacia la ciencia en la educación STEM en niños y niñas de 10 a 14 años. Diseño y validación de un instrumento de medida [Attitudes towards science in STEM education in boys and girls from 10 to 14 years old. Design and validation of a measurement 
instrument] [Doctoral thesis, Comillas Universidad Pontificia].

National Aeronautics and Space Administration-NASA. (2016). Kites. Principles of flight: Kites (Grades 5-12). https://www.nasa.gov/sites/default/files/atoms / files/kites_5-12-v2.pdf

National Council of Teachers of Mathematics-NCTM. (2000). Principles and standards for school mathematics. National Council of Teachers of Mathematics.

Oliveras, M., \& Godino, J. D. (2015). Comparando el programa etnomatemático y el enfoque ontosemiótico: Un esbozo de análisis mutuo [Comparing the ethnomathematical program and the ontosemiotic approach: An outline of mutual analysis]. Revista Latinoamericana de Etnomatemática [Latin American Journal of Ethnomathematics], 8(2), $432-449$.

Parjanadze, N. (2009). Globalisation theories and their effect on education. IBSU Scientific Journal, 2(3), 7788.

Paternina-Borja, O., Muñoz-Granados, N., PachecoMuñoz, E., \& Aroca, A. (2020). Simetrías inmersas en el proceso de la elaboración de la máscara del torito de Galapa [Symmetries immersed in the process of making the mask of the Galapa bull]. Revista de Investigación, Desarrollo e Innovación [Journal of Research, Development and Innovation], 11(1), 141-157. https:/ / doi.org/10.19053/20278306. v11.n1.2020.11689

Prediger, S., Bikner-Ahsbahs, A., \& Arzarello, F. (2008). Networking strategies and methods for connection theoretical approaches: First steps towards a conceptual framework. ZDM Mathematics Education, 40(2), 165-178. https:/ / doi.org/10.1007/ s11858-008-0086-Z

Radford, L. (2008). Connecting theories in mathematics education: challenges and possibilities. ZDM Mathematics Education, 40, 317-327. https:/ / doi.org /10.1007/s11858-008-0090-3

Restrepo, E. (2016). Etnografía: Alcances, técnicas y éticas [Ethnography: Scope, techniques and ethics]. Envión Editores.

Rey, M., \& Aroca, A. (2011). Medición y estimación de los albañiles, un aporte a la educación matemática [Measurement and estimation of masons, a contribution to mathematics education]. Revista U.D.C.A Actualidad \& Divulgación Científica [U.D.C.A Journal News \& Scientific Dissemination], 14(1), 137-147. https://doi.org/10.31910/rudca. v14.n1.2011.766

Rodríguez-Nieto, C. A. (2020). Explorando las conexiones entre sistemas de medidas usados en prácticas cotidianas en el municipio de Baranoa [Exploring the connections between measurement systems used in daily practices in the municipality of Baranoa]. IE Revista de Investigación Educativa de la REDIECH [IE Journal of Educational Research of the REDIECH], 11, e-857. https://doi.org/10.33010/ ie_rie_rediech.v11i0.857

Rodríguez-Nieto, C. A. (2021). Conexiones etnomatemáticas entre conceptos geométricos en la elaboración de las tortillas de Chilpancingo, México. Revista de investigación desarrollo e innovación [Journal of Research, Development and Innovation], 11(2), 273-296. https://doi.org/ 10.19053/20278306.v11.n2.2021.12756

Rodríguez-Nieto, C. A., Rodríguez-Vásquez, F. M., \& García-García, J. (2021a). Pre-service mathematics teachers' mathematical connections in the context of problem-solving about the derivative. Turkish Journal of Computer and Mathematics Education, 12(1), 202-220.

https:/ / doi.org/10.16949/turkbilmat.797182

Rodríguez-Nieto, C., Aroca, A., \& Rodríguez-Vásquez, F. M. (2019a). Procesos de medición en una práctica artesanal del caribe colombiano. Un estudio desde la etnomatemática [Measurement processes in an artisanal practice of the Colombian Caribbean. A study from ethnomathematics]. Revista Latinoamericana de Etnomatemática [Latin American Journal of Ethnomathematics], 12(4), 61-88. https:/ / doi.org/10.22267/ relatem.19124.36

Rodríguez-Nieto, C., Font, V., Borji, V., \& RodríguezVásquez, F. M. (2021b). Mathematical connections from a networking theory between Extended Theory of Mathematical connections and Ontosemiotic Approach. International Journal of Mathematical Education in Science and Technology. https:/ / doi.org/10.1080/0020739X.2020.1799254

Rodríguez-Nieto, C., Mosquera-García, G., \& Aroca, A. (2019b). Dos sistemas de medidas no convencionales en la pesca artesanal con cometa en Bocas de Cenizas [Two systems of nonconventional measures in artisanal kite fishing in Bocas de Cenizas]. Revista Latinoamericana de Etnomatemática [Latin American Journal of Ethnomathematics], 12(1), 6-24.

Rodríguez-Nieto, C., Rodríguez-Vásquez, F. M., \& Font, V. (2020). A new view about connections. The mathematical connections established by a teacher when teaching the derivative. International Journal of Mathematical Education in Science and Technology, https:// doi.org/10.1080/0020739X.2020.1799254

Rodríguez-Nieto, C., Rodríguez-Vásquez, F. M., \& García-García, J. (2021c). Exploring university Mexican students' quality of intra-mathematical connections when solving tasks about derivative concept. EURASIA Journal of Mathematics, Science and Technology Education, 17(9), em2006. https://doi.org/10.29333/ejmste/11160 
Rosa, M., \& Orey, D. (2016). Polysemic Interactions between Ethnomathematics and Culturally Relevant Pedagogy. In M. Rosa, U. D’Ambrosio, D. C. Orey, L. Shirley, W. V. Alangui, P. Palhares, \& M. E. Gavarrete (Eds.), State of the Art in Ethnomathematics (pp. 11-13). Springer International Publishing.

Rosa, M., \& Orey, D. (2016). State of the art in ethnomathematics. In M. Rosa, U. D'Ambrosio, D. C. Orey, L. Shirley, W. V. Alangui, P. Palhares, \& M. Gavarrete (Eds.), Current and future perspectives of ethnomathematics as a program. ICME-13 topical surveys. Springer. https://doi.org/10.1007/978-3319-30120-4_3

Rosa, M., \& Orey, D. (2018). Propondo um currículo trívium fundamentado nas perspectivas da etnomatemática e da modelagem [Proposing a trivium curriculum based on the perspectives of ethnomathematics and modeling]. Revista Educação Matemática en Foco [Mathematics Education Journal in Focus], 7(2), 63-98.

Rosa, M., \& Orey, D. (2021). An ethnomathematical perspective of STEM education in a glocalized world. Bolema: Boletim de Educação Matemática [Bolema: Mathematics Education Bulletin], 35, 840-876. https:/ / doi.org/10.1590/1980-4415v35n70a14

Rosa, M., \& Shirley, L. (2016). Polysemic interactions between ethnomathematics and culturally Relevant pedagogy. In M. Rosa, U. D'Ambrosio, D. C. Orey, L. Shirley, W. V. Alangui, P. Palhares, \& M. E. Gavarrete (Eds.), Introduction (pp. 1-3). Springer.

Sánchez-Ludeña, E. (2019). La educación STEAM y la cultura «maker» [STEAM education and the "maker" culture]. Revista de Padres y Maestros [Journal of Parents and Teachers], (379), 4551. https:/ / doi.org/10.14422/pym.i379.y2019.008

Sunzuma, G., \& Maharaj, A. (2019). Teacher-related challenges affecting the integration of ethnomathematics approaches into the teaching of geometry. Eurasia Journal of Mathematics, Science and Technology Education, 15(9), em1744. https:/ / doi.org/10.29333/ ejmste/108457

Sunzuma, G., \& Maharaj, A. (2020). In-service secondary teachers' teaching approaches and views towards integrating ethnomathematics Approaches into geometry teaching. Bolema: Boletim de Educação Matemática [Bolema: Mathematics Education Bulletin], 34, 22-39. https://doi.org/10.1590/19804415v34n66a02

Supiyati, S., Hanum, F., \& Jailani, J. (2019). Ethnomathematics in Sasaknese architecture. Journal on Mathematics Education, 10(1), 47-58. https:/ / doi.org/10.22342/jme.10.1.5383.47-58

Tabach, M., Rasmussen, C., Dreyfus, T., \& Apkarian, N. (2020). Towards an argumentative grammar for networking: A case of coordinating two approaches. Educational Studies in Mathematics, 103(6). https:/ / doi.org/10.1007/s10649-020-099347

Tsupros, N., Kohler, R., \& Hallinen, J. (2009). STEM education: A project to identify the missing components. Intermediate Unit, 1, 11-17.

Umbara, U., Wahyudin, W., \& Prabawanto, S. (2021). Exploring ethnomathematics with ethnomodeling methodological approach: How does cigugur indigenous people using calculations to determine good day to build houses. EURASIA Journal of Mathematics, Science and Technology Education, 17(2), em1939. https:// doi.org/10.29333/ejmste/9673

Vásquez, J., Sneider, C., \& Comer, M. (2013). STEM lesson essentials, grades 3-8: Integrating science, technology, engineering, and mathematics. Heinemann.

Wagner, D., \& Flores, C. (2020). (Re)inventando a relação matemática e arte: Exercícios de pensamento, exercícios de olhar [(Re)inventing the relationship between mathematics and art: Thinking exercises, looking exercises]. Revista Eletrônica de Educação Matemática [Electronic Mathematics Education Journal], 15(1), 1-19. https://doi.org/10.5007/ 1981-1322.2020.e67911

Zabala, A. (1999). Enfoque globalizador y pensamiento complejo. Una propuesta para la comprensión e intervención en la realidad [Globalization approach and complex thinking. A proposal for understanding and intervening in reality]. Editorial Graó.

Zollman, A. (2012). Learning for STEM literacy: STEM literacy for learning. School Science and Mathematics, 112(1), 12-19. https://doi.org/10.1111/j.19498594.2012.00101.x

\section{https://www.ejmste.com}

